\title{
Real effects of an international tax reform for MNEs *
}

\author{
Regina Ortmann
}

Paderborn University ${ }^{\dagger}$

\section{Dirk Simons}

University of Mannheim $\ddagger$

\author{
Dennis Voeller
}

Toulouse Business School $\$$

\section{Working Paper - October, 2021}

With multinational enterprises (MNEs) centralizing production facilities, market countries claim not to receive their fair share of taxes. A reform of international business taxation that includes new profit allocation rules as well as the introduction of minimum taxation is being considered as a problem mitigating mechanism. We analyze theoretically the real effects of the aforementioned tax reform, i.e., MNEs' adjustments of production and sales decisions. Our findings show that the effects of an international tax reform on sales quantities depend on the properties of the underlying product markets. If national demand resembles characteristics of traditional industries, sales quantities remain unchanged. However, sales quantities are affected if specific demand characteristics of modern business models are assumed. For traditional industries a reformed tax regime increases tax revenues in high-tax market countries and even attracts production. For modern business models tax revenues of low-tax countries can even increase.

JEL-Classification: C70, H26, H32, M48

Keywords: BEPS, corporate taxation, minimum taxation, profit shifting, tax avoidance

\footnotetext{
*The authors gratefully acknowledge financial support by the German Research Foundation (DFG) - Collaborative Research Center (SFB/TRR) Project-ID 403041268 - TRR 266 Accounting for Transparency. They also thank Sebastian Kronenberger (TRR Conference discussant), Stacie Laplante, and participants at the 2020 TRR 266 Annual Conference, the EAA Annual Congress 2021, as well as workshop participants at ESCP Business School, WHU - Otto Beisheim School of Management, and the University of Toulouse for their valuable comments and suggestions.

†Warburger Str. 100, 33098 Paderborn, Germany; +49 525160 1780; regina.ortmann@upb.de

${ }^{\ddagger}$ Schloss Ostfluegel, 68131 Mannheim, Germany; +49 621 181 1663; simons@bwl.uni-mannheim.de

§1 Place Alfonse Jourdain, 31000 Toulouse, France; +33 561294 740; d.voeller@tbs-education.fr
} 


\section{Real effects of an international tax reform for MNEs}

\author{
Regina Ortmann
}

Paderborn University *

\author{
Dirk Simons
}

University of Mannheim ${ }^{\dagger}$

\author{
Dennis Voeller
}

Toulouse Business School ${ }^{\ddagger}$

$$
\text { Working Paper - October, } 2021
$$

Comme des entreprises multinationales centralisent leur production, de nombreux États de marché craignent de ne pas recevoir leur juste part des recettes fiscales. Une réforme internationale de la fiscalité des entreprises, qui comprend de nouvelles règles sur la répartition des bénéfices ainsi que l'introduction d'un impôt minimum, est considérée comme une solution possible. Nous analysons théoriquement les effets réels de la réforme fiscale susmentionnée, c'est-à-dire les ajustements des décisions de production et de vente des multinationales. Nos résultats montrent que les effets d'une réforme fiscale internationale sur les quantités vendues dépendent des propriétés des marchés de produits sous-jacents. Si la demande nationale ressemble aux caractéristiques des industries traditionnelles, les quantités vendues restent inchangées. En revanche, les quantités vendues sont affectées si des caractéristiques spécifiques de la demande pour les modèles commerciaux modernes sont prises en compte. Pour les industries traditionnelles, un régime fiscal réformé augmente les recettes fiscales dans les pays à fiscalité levée et attire même la production. En revanche, pour les modèles commerciaux modernes, les recettes fiscales des pays à forte imposition peuvent même diminuer.

JEL-Classification: C70, H26, H32, M48

Keywords: BEPS, évitement fiscal, fiscalité des entreprises, impôt minimum, transfert de bénéfices

\footnotetext{
*Warburger Str. 100, 33098 Paderborn, Germany; +49 525160 1780; regina.ortmann@upb.de

†Schloss Ostfluegel, 68131 Mannheim, Germany; +49 621 181 1663; simons@bwl.uni-mannheim.de

†1 Place Alfonse Jourdain, 31000 Toulouse, France; +33 561 294 740; d.voeller@tbs-education.fr
} 


\section{Introduction}

Cross-border sales have gained increasing attention (see OECD (2018)), because production of foreign affiliates tripled, recently. Moreover, the major part of outward production is controlled by multinational enterprises (MNEs) domiciled in just a few developed countries. ${ }^{1}$ As MNEs often centralize production the only economic activity in market countries is sales - typically compensated by cost-plus or resale-minus based transfer prices. From a tax revenue perspective, many market states believe not to receive their fair share because of transfer prices being prone to profit-shifting. ${ }^{2}$

To ensure a more fair and just allocation of taxation rights a concept for a two-pillar solution to address global tax challenges has been accepted by the OECD and G 20 in July 2021 (OECD, 2021). ${ }^{3}$ A detailed implementation plan will be published in October 2021. If members agree, this reform will be brought into law in 2022, to be effective in 2023 . The OECD concept rests on two pillars: Pillar One aims at sourcing more revenues to market jurisdictions where goods or services are used or consumed. The OECD envisages a closer link between the allocation of an MNE's taxable income and the distribution of sales. ${ }^{4}$ Pillar Two stipulates the introduction of a global minimum tax.

However, an effective reform has to anticipate MNEs' reactions to a change in the taxation regime. In terms of production, firms could build up capacities located in market countries or withdraw from those markets in fear of local tax authorities pushing for higher tax payments. In this paper, we investigate the impact of an international tax reform on the (de)centralization of production operations, on sales quantities and on transfer pricing decisions. We analyze these key decisions based on a two-country model with a single-product MNE. In a first setting, we model traditional product markets, where local prices are independent from sales quantities in the other country. In a second setting, we consider national sales as complements reflecting demand characteristics of modern product markets, e.g. for social network services. We always focus on how the MNE anticipates tax measures by adjusting the location of production, sales and transfer prices.

Our paper is related to two streams of literature: First, our paper responds to the call for research on tax effects on the business activities of MNEs (Dyreng and Maydew, 2018). Specifically, we contribute to the growing literature on minimum

\footnotetext{
${ }^{1}$ These countries are the US, the UK, Germany, France, Japan, Switzerland and the Netherlands.

${ }^{2}$ See, e.g., Merle (2016) or Norris (2013).

${ }^{3}$ Digital service taxes can be regarded as unilateral attempts to secure taxation rights that would become superfluous after a global tax reform. See, e.g., Cui and Hashimzade (2019).

${ }^{4}$ On the importance of a global accord on the applicable tax base, see, e.g., Bunn (2021).
} 
taxation (see, for example, Scot et al. (2020); Li (2018); Best et al. (2015)). Second, by analyzing the choice between centralized and decentralized production we contribute to the literature concerned with tax-induced distortions of investment. In line with the focus of our paper, Marques et al. (2019) assess the extent to which real investment responsiveness to corporate taxation is affected by cross-border income shifting. Altering production locations as a reaction to changes in tax regimes replicates this decision problem in our model. However, our results largely depend on the product market characteristics above and beyond the installed tax regime. Our paper also extends Martini et al. (2012) who analyze the impact of different combinations of tax allocation and managerial accounting regimes on investment and production decisions under Formula Apportionment (FA). In contrast to them we consider effects of a minimum taxation regime.

Our results show that the effects of the aforementioned international tax reform on sales quantities depend on the properties of the underlying product markets. If national demand resembles characteristics of traditional industries, sales quantities remain unchanged. Here, the MNE only adjusts its transfer prices reacting to the introduction of the new taxation regime. On the contrary, sales quantities are affected if specific demand characteristics of modern business models are assumed. Further, for traditional industries the tax reform increases tax revenues in the high-tax market country, and even attracts production facilities. Applied to modern business models tax revenues of the low-tax market country can even increase after the reform. Finally, our results suggest that the mere threat to be taxed according to a sales formula results in adjustments of MNEs' production location, sales quantities, and transfer prices.

The paper proceeds as follows. In section 2 we consider traditional business models where national sales are independent from global activities, i.e. separability of domestic and foreign sales is given. After analyzing a pre-tax regime, we consider a regular corporate taxation regime. Finally, we investigate a minimum taxation regime after an international tax reform that advances minimum taxation by means of a sales-based reallocation of taxable income. Following the same structure, section 3 explicitly considers complementarities between national sales which are a common characteristic of many modern business models (see for example Hein et al. (2020)). In section 4 we compare the results across the settings and discuss potential implications for fiscal policy. Section 5 concludes. 


\section{Separability of foreign and domestic sales}

We consider a multinational enterprise that produces and sells a single product in two countries $i, i \in\{A, B\}$. The MNE centralizes decisions on both production quantities $x_{i}$ and sales quantities $s_{i}$. We assume a single-stage production process with production taking place either in country $A$ (centralized production) or in both countries simultaneously (decentralized production). The applied inverse demand function reflects characteristics of traditional product markets, i.e., sales in one country do not affect sales in the other country. The local sales price $p_{i}^{\text {sep }}$ is determined as:

$$
p_{i}^{s e p}\left(s_{i}\right)=d_{i}-s_{i}
$$

The parameter $d_{i}$ denotes the maximum willingness to pay and indirectly reflects market size. Further, we assume constant unit production cost, $c_{i}$, neglecting fixed costs. Moreover, in case of goods being exported, transaction costs of $c_{T}$ per unit apply. We consider only profitable sales, i.e. $p_{i}^{\text {sep }}\left(s_{i}\right)>c_{i}$ or, if applicable, $p_{B}^{\text {sep }}\left(s_{i}\right)>c_{A}+c_{T}$. Transactions costs are borne by the receiving entity $B$. For ease of presentation we assume the exporting country to be $A$ (if necessary), implying that $x_{A} \geq s_{A}$. We exclude stockkeeping and backorder sales. Thus, the quantity of imported goods, $q_{B}=x_{A}-s_{A}$, added to the domestic production in country $\mathrm{B}, x_{B}$, has to meet the local demand, i.e., $x_{B}+q_{B}=s_{B}$. The total transfer payment, $T\left(q_{B}\right)$ for all exported goods, $q_{B}$, amounts to $T\left(q_{B}\right)=t q_{B}$, with $t$ reflecting the transfer price per unit. ${ }^{5}$ Thus, the total profit $\Pi^{\text {no,sep }}\left(s_{A}, s_{B}, q_{B}\right)$ in a pre-tax regime reads:

$$
\begin{aligned}
\Pi^{\text {no,sep }}(\cdot) & =\underbrace{\left(d_{A}-s_{A}\right) s_{A}+t q_{B}-c_{A} x_{A}}_{\Pi_{A}^{\text {no,sep }}}+\underbrace{\left(d_{B}-s_{B}\right) s_{B}-t q_{B}-c_{B} x_{B}-c_{T} q_{B}}_{\Pi_{B}^{\text {no,sep }}} \\
& =\left(d_{A}-s_{A}\right) s_{A}-c_{A}\left(s_{A}+q_{B}\right)+\left(d_{B}-s_{B}\right) s_{B}-c_{B}\left(s_{B}-q_{B}\right)-c_{T} q_{B}
\end{aligned}
$$

Thereby, the first three terms in the upper line of (2) represent the reported profit in country $A, \Pi_{A}^{n o, s e p}$; the next four terms represent the reported profit in country $B, \Pi_{B}^{n o, s e p}$, with the last term accounting for potential transaction costs. Observe the well-known effect that in the absence of taxation, transfer prices do not affect the overall profit of the $M N E$.

With corporate tax rates $\left.\tau_{i} \in\right] 0,1\left[\right.$, and $\tau_{A} \neq \tau_{B}$ applied to reported profits, the total

\footnotetext{
${ }^{5}$ The applied transfer price could result from cost-plus, i.e., $c_{A}+\varepsilon$, or from resale-minus, i.e., $p_{B}-\varepsilon$.
} 
profit $\Pi^{\operatorname{tax}, \text { sep }}\left(s_{A}, s_{B}, q_{B}\right)$ in the corporate tax regime changes to:

$$
\begin{aligned}
\Pi^{\text {tax,sep }}(\cdot) & =\Pi_{A}^{n o, \text { sep }}\left(1-\tau_{A}\right)+\Pi_{B}^{n o, s e p}\left(1-\tau_{B}\right) \\
& =\left[\left(d_{A}-s_{A}\right) s_{A}+t q_{B}-c_{A}\left(s_{A}+q_{B}\right)\right]\left(1-\tau_{A}\right) \\
& +\left[\left(d_{B}-s_{B}\right) s_{B}-t q_{B}-c_{B}\left(s_{B}-q_{B}\right)-c_{T} q_{B}\right]\left(1-\tau_{B}\right)
\end{aligned}
$$

As there exists no theoretically justified benchmark for transfer prices, ${ }^{6}$ every legally accepted transfer price is a political compromise reflecting negotiation power, fairness considerations and current development conditions of the involved countries. In our model, transfer prices are accepted by the local fiscal authorities whenever the export of goods or services has non-negative effects on national tax bases, i.e., $t \in[\underline{t}, \bar{t}]=\left[c_{A}, d_{B}-\right.$ $\left.s_{B}-c_{T}\right]$. We assume that both tax authorities are bound to this range irrespective of the fiscal regime. This assumption excludes an abuse of a specific fiscal regime, such as minimum taxation, on behalf of the fiscal authorities.

In the minimum taxation regime the local tax base rests on a sales based allocation formula. Sales are widely believed to be a good proxy for allocating profits: ${ }^{7}$ First of all, revenues are less prone to manipulation than profits, total book-value of assets or employees' compensation. Second, companies are not discouraged to expand their property and payroll as these criteria do not enter the tax formula (Andrus and Oosterhuis, 2017; Goolsbee and Maydew, 2000). Third, sales-based formulas have been widely accepted in real life. ${ }^{8}$ Finally, market countries lobby for sales-based allocations of taxation rights emphasizing the economic value of the customer-base in the current political discussions (see, e.g., GrantThornton (2019), OECD (2021)).

Accordingly, the minimum required tax base, $T B_{i}$ is:

$$
T B_{i}=\frac{p_{i} s_{i}}{p_{i} s_{i}+p_{\neg i} S_{\neg i}}\left(\Pi_{i}^{n o}+\Pi_{\neg i}^{n o}\right)
$$

Observe that (4) implies $T B_{\neg i}=\left(1-\frac{p_{i} s_{i}}{p_{i} s_{i}+p_{\neg i} \Im_{\neg i}}\right)\left(\Pi_{i}^{n o}+\Pi_{\neg i}^{n o}\right)$ for identical apportionment formulas. ${ }^{9}$ Specifically, country $i$ compares the reported local profit to

\footnotetext{
${ }^{6}$ For a technical proof see Alchian and Demsetz (1972).

${ }^{7}$ For a discussion of the advantages and disadvantages of this factor, see, for example, Radaelli and Klemm (2001).

${ }^{8}$ In the U.S., a majority of states heavily relies on sales factors for inter-state profit allocation (Clausing, 2016).

${ }^{9}$ Focusing on effects of information endowment, we eliminate any confounding effects from applying the allocation formula. Therefore, we do not allow for different formulas in different countries.
} 
the minimum tax base and potentially adjusts the local profit upwards:

$$
\Pi_{i}^{\min }(\cdot)= \begin{cases}\frac{p_{i} s_{i}}{p_{i} s_{i}+p_{\neg i} s_{\neg i}}\left(\Pi_{i}^{n o}+\Pi_{\neg i}^{n o}\right) & \text { if } \Pi_{i}^{n o} \leq T B_{i} \\ \Pi_{i}^{n o} & \text { if } \Pi_{i}^{n o}>T B_{i}\end{cases}
$$

Accordingly, the total after-tax profit with minimum taxation reads as follows:

$$
\Pi^{\min }(\cdot)= \begin{cases}\Pi_{i}^{n o}-\frac{p_{i} s_{i}}{p_{i} s_{i}+p_{\neg i} s_{\neg i}}\left(\Pi_{i}^{n o}+\Pi_{\neg i}^{n o}\right) \tau_{i}+\Pi_{\neg i}^{n o}\left(1-\tau_{\neg i}\right) & \text { if } \Pi_{i}^{n o} \leq T B_{i} \\ \Pi_{i}^{n o}\left(1-\tau_{i}\right)+\Pi_{\neg i}^{n o}-\frac{p_{\neg i} s_{\neg i}}{p_{i} s_{i}+p_{\neg i} s_{\neg i}}\left(\Pi_{i}^{n o}+\Pi_{\neg i}^{n o}\right) \tau_{\neg i} & \text { if } \Pi_{i}^{n o}>T B_{i}\end{cases}
$$

Lemma 1 shows our results for the pre-tax regime without taxation as derived from (2).

Lemma 1. In the pre-tax regime, the MNE centralizes production, with $x_{A}=s_{A}+s_{B}$, if

$$
c_{B}>c_{A}+c_{T}
$$

The optimal sales quantities are:

$$
s_{A}^{*}=\frac{1}{2}\left(d_{A}-c_{A}\right) \text { and } s_{B}^{*}=\left\{\begin{array}{cc}
\frac{1}{2}\left(d_{B}-c_{A}-c_{T}\right) & \text { for centralized production } \\
\frac{1}{2}\left(d_{B}-c_{B}\right) & \text { for decentralized production }
\end{array}\right.
$$

Proof: See Appendix A.1 and setting $\alpha_{i}=0$.

Lemma 2 summarizes our findings for a regime where reported profits are taxed at tax rates $\tau_{i}$, as represented by (3).

Lemma 2. In a regime with corporate income taxation at rates $\tau_{i}$, the MNE centralizes production if

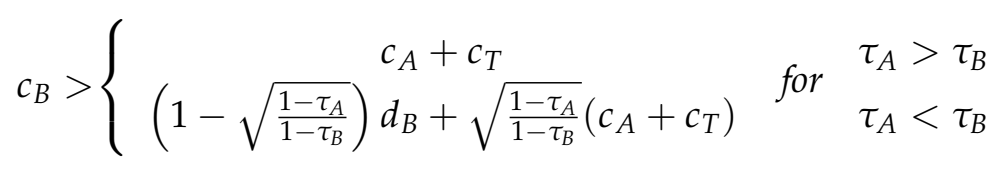

The optimal transfer price $t^{*}$ under centralized production is

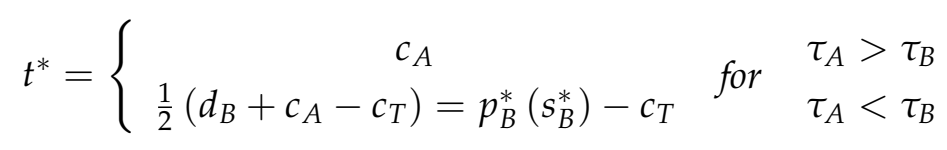

The optimal sales quantities are

$$
s_{A}^{*}=\frac{1}{2}\left(d_{A}-c_{A}\right) \text { and } s_{B}^{*}=\left\{\begin{array}{cc}
\frac{1}{2}\left(d_{B}-c_{A}-c_{T}\right) & \text { for centralized production } \\
\frac{1}{2}\left(d_{B}-c_{B}\right) & \text { for decentralized production }
\end{array}\right.
$$


The resulting tax revenues $\mathcal{T}_{A}$ in country $A$ are

$$
\mathcal{T}_{A}=\left\{\begin{array}{cc}
\frac{1}{4} \tau_{A}\left(d_{A}-c_{A}\right)^{2} & \text { for decentralized production } \\
\frac{1}{4} \tau_{A}\left(d_{A}-c_{A}\right)^{2} & \text { for centralized production and }\left\{\begin{array}{l}
\tau_{A}>\tau_{B} \\
\tau_{A}<\tau_{B}
\end{array}\right.
\end{array}\right.
$$

The resulting tax revenues $\mathcal{T}_{B}$ in country $B$ are

$$
\mathcal{T}_{B}=\left\{\begin{array}{cr}
\frac{1}{4} \tau_{B}\left(d_{B}-c_{B}\right)^{2} & \text { for decentralized production } \\
\frac{1}{4} \tau_{B}\left(d_{B}-c_{A}-c_{T}\right)^{2} & \text { for centralized production and }\left\{\begin{array}{l}
\tau_{A}>\tau_{B} \\
\tau_{A}<\tau_{B}
\end{array}\right.
\end{array}\right.
$$

Proof: See Appendix A.2 and setting $\alpha_{i}=0$.

(11) shows that sales quantities remain unchanged compared to the pre-tax regime. (9) shows that the location decision remains unaffected as long as $\tau_{A}>\tau_{B}$. If $\tau_{A}<\tau_{B}$, comparing the threshold for the unit production $\operatorname{costs} c_{B}$ in the pre-tax case, (7), with the one of the corporate tax regime, (9), reveals:

$$
c_{A}+c_{T}>d_{B}-\left(d_{B}-c_{A}-c_{T}\right) \sqrt{\frac{1-\tau_{A}}{1-\tau_{B}}} \Leftrightarrow c_{A}+c_{T}<d_{B}
$$

The latter inequality is true by assumption. The lower threshold in the corporate tax regime indicates that the $M N E$ centralizes production more often than in the pre-tax regime. Thus, country $A$ is able to attract production facilities by ways of a lower tax rate.

Changing the legal framework and introducing the possibility of minimum taxation has the following effects.

Lemma 3. If minimum taxation is feasible, let $d_{B} \leq\left(1+\frac{c_{T}}{c_{A}}\right) d_{A}$ and $c_{B}>c_{A}+c_{T}$. Then, production is centralized.

The optimal transfer price $t^{*}$ is

$$
t^{*}=c_{A}
$$

The optimal sales quantities are

$$
s_{A}^{*}=\frac{1}{2}\left(d_{A}-c_{A}\right) \text { and } s_{B}^{*}=\frac{1}{2}\left(d_{B}-c_{A}-c_{T}\right)
$$


The resulting tax revenues $\mathcal{T}_{\text {min }}$ in countries $A$ and $B$ are

$$
\mathcal{T}_{\text {min }}=\left\{\begin{array}{cc}
\frac{1}{4} \tau_{A}\left(d_{A}-c_{A}\right)^{2} & \text { in country } A \\
\frac{1}{4} \tau_{B}\left(d_{B}-c_{A}-c_{T}\right)^{2} & \text { in country } B
\end{array}\right.
$$

For $d_{B} \leq\left(1+\frac{c_{T}}{c_{A}}\right) d_{A}$ and $c_{B}<c_{A}+c_{T}$ decentralized production is optimal. The optimal sales quantities of Lemma 2 apply.

Proof: See Appendix A.3 with $\alpha_{i}=0$

Due to the feasibility of minimum taxation location incentives stemming from the corporate income taxation regime are nullified as long as $d_{B} \leq\left(1+\frac{c_{T}}{c_{A}}\right) d_{A}$. That is, compared to the corporate income taxation regime the feasibility of minimum taxation re-establishes incentives to decentralize production. For $\tau_{A}<\tau_{B}$, this implies that $A$ loses production capacities to $B$. Moreover, tax revenues decrease in country $A$ and increase in $B$ due to the mere possibility of applying a sales based formula. Note that here no country actually applies the sales formula to determine its tax base due to the anticipation of the MNE. Only if the $d_{B}$-threshold is exceeded, both countries would determine taxable income based on sales, which is beyond the scope of this paper. Tax revenues of both countries do not change for $\tau_{B}<\tau_{A}$ under a minimum tax regime as long as the $d_{B}$-threshold is not exceeded.

\section{Complementarities between foreign and domestic sales}

The previous analyses are based on separable national sales. That is, at least in the absence of taxes, a change in sales in country $A$ does not affect price and sales quantity in country $B$, and vice versa. In this section, we integrate complementarities between foreign and domestic sales. ${ }^{10}$

Modern business models such as digital service platforms often generate customer value because of network effects. This implies that national demand is downwardsloping in the charged price, but upward-sloping in the number of total users. Thus, demand can be quantified as:

$$
s_{i}\left(p_{i}, s_{\neg i}\right)=d_{i}-p_{i}+\alpha_{i} s_{\neg i}+\beta_{i} s_{i}
$$

Here, $\alpha_{i}\left(\beta_{i}\right)$ is a scaling parameter indicating the strength of the network effect in country $i$ from foreign (domestic) sales. Deriving the inverse demand function from

\footnotetext{
${ }^{10}$ If not stated otherwise the assumptions and model settings of the previous section hold.
} 
(18) by suppressing factor $\left(1-\beta_{i}\right)$, which only scales the price impact of local sales, and re-arranging terms gives:

$$
p_{i}\left(s_{i}, s_{\neg i}\right)=d_{i}-s_{i}+\alpha_{i} s_{\neg i}
$$

where $0<\alpha_{i}<1$ is assumed. Thus, the total profit in the pre-tax regime, $\Pi^{n o, c o}\left(s_{A}, s_{B}, q_{B}\right)$, reads:

$$
\begin{aligned}
\Pi^{n o, c o}(\cdot) & =\underbrace{\left(d_{A}-s_{A}+\alpha_{A} s_{B}\right) s_{A}+t q_{B}-c_{A} x_{A}}_{\Pi_{A}^{\text {no,co }}} \\
& +\underbrace{\left(d_{B}-s_{B}+\alpha_{B} s_{A}\right) s_{B}-t q_{B}-c_{B} x_{B}-c_{T} q_{B}}_{\Pi_{B}^{\text {no,co }}} \\
& =\left(d_{A}-s_{A}+\alpha_{A} s_{B}\right) s_{A}-c_{A}\left(s_{A}+q_{B}\right) \\
& +\left(d_{B}-s_{B}+\alpha_{B} s_{A}\right) s_{B}-c_{B}\left(s_{B}-q_{B}\right)-c_{T} q_{B}
\end{aligned}
$$

Analogously, the total profit in the corporate tax regime, $\Pi^{\operatorname{tax}, c o}\left(s_{A}, s_{B}, q_{B}\right)$, reads:

$$
\begin{aligned}
\Pi^{t a x, c o}(\cdot) & =\Pi_{A}^{n o, c o}\left(1-\tau_{A}\right)+\Pi_{B}^{n o, c o}\left(1-\tau_{B}\right) \\
& =\left[\left(d_{A}-s_{A}+\alpha_{A} s_{B}\right) s_{A}+t q_{B}-c_{A}\left(s_{A}+q_{B}\right)\right]\left(1-\tau_{A}\right) \\
& +\left[\left(d_{B}-s_{B}+\alpha_{B} s_{A}\right) s_{B}-t q_{B}-c_{B}\left(s_{B}-q_{B}\right)-c_{T} q_{B}\right]\left(1-\tau_{B}\right)
\end{aligned}
$$

Transfer prices are accepted by the local fiscal authorities whenever the export of goods has non-negative effects on national tax bases, i.e., $t \in[\underline{t}, \bar{t}]=\left[c_{A}, d_{B}-s_{B}+\alpha_{B} s_{A}-\right.$ $\left.c_{T}\right]$. The rules for minimum taxation apply analogously.

\subsection{Pre-tax regime}

To analyze the effects of complementarities between national sales, our benchmark regime is a regime without taxes based on profit function (20). Lemma 4 summarizes the findings.

Lemma 4. The MNE chooses centralized production, with $x_{A}=s_{A}+s_{B}$, if

$$
c_{B}>c_{A}+c_{T}
$$

The optimal sales quantities are

$$
s_{A}^{*}=\left\{\begin{array}{cc}
\frac{2\left(d_{A}-c_{A}\right)+\left(d_{B}-c_{A}-c_{T}\right)\left(\alpha_{A}+\alpha_{B}\right)}{4-\left(\alpha_{A}+\alpha_{B}\right)^{2}} & \text { for centralized production } \\
\frac{2\left(d_{A}-c_{A}\right)+\left(d_{B}-c_{B}\right)\left(\alpha_{A}+\alpha_{B}\right)}{4-\left(\alpha_{A}+\alpha_{B}\right)^{2}} & \text { for decentralized production }
\end{array}\right.
$$


and

$$
s_{B}^{*}=\left\{\begin{array}{cc}
\frac{2\left(d_{B}-c_{A}-c_{T}\right)+\left(d_{A}-c_{A}\right)\left(\alpha_{A}+\alpha_{B}\right)}{4-\left(\alpha_{A}+\alpha_{B}\right)^{2}} & \text { for centralized production } \\
\frac{2\left(d_{B}-c_{B}\right)+\left(d_{A}-c_{A}\right)\left(\alpha_{A}+\alpha_{B}\right)}{4-\left(\alpha_{A}+\alpha_{B}\right)^{2}} & \text { for decentralized production }
\end{array}\right.
$$

Proof: See Appendix A.1.

The results show that different from section 2, complementarities in international sales lead to different sales quantities depending on the firm's choice of a centralized or decentralized production process not only in country $B$, but in the exporting country $A$ as well.

Comparing the first terms in the numerators of the centralized and the decentralized production quantities in (24) shows the direct effect of cost differences between centralized and decentralized production on the sales quantity $s_{B}^{*}$. The second term in the numerator in (24) shows the indirect ("complementary") effect of the sales in $A$ (which depend on $d_{A}, c_{A}$ and $\alpha_{A / B}$ ) on the sales in $B$.

\subsection{Corporate income tax regime}

In this section we assume that reported profits $\Pi_{i}^{n o, c o}$ are taxed at corporate tax rates $\tau_{i}$. By means of transfer pricing the MNE can shift profits between the countries.

Lemma 5. In a regime with corporate income taxation at rates $\tau_{i}$, the $M N E$ chooses centralized production if

$c_{B}>\left\{\begin{array}{lll}c_{A}+c_{T} & \tau_{A}>\tau_{B} \\ \frac{1}{2}\left(d_{A}-c_{A}\right)\left(\alpha_{A} \frac{1-\tau_{A}}{1-\tau_{B}}+\alpha_{B}\right)+d_{B}-s_{B}^{*} \frac{2 \sqrt{4-\left(\alpha_{A}+\alpha_{B}\right)^{2}}}{\left(1-\tau_{B}\right)} & \text { for } & \tau_{A}<\tau_{B} \\ \cdot \sqrt{\left(4-2 \alpha_{A} \alpha_{B}\right)\left(1-\tau_{A}\right)\left(1-\tau_{B}\right)-\alpha_{A}^{2}\left(1-\tau_{A}\right)^{2}-\alpha_{B}^{2}\left(1-\tau_{B}\right)^{2}} & \end{array}\right.$

The optimal transfer price $t^{*}$ under centralized production is

$$
t^{*}=\left\{\begin{array}{ccc}
c_{A} & \tau_{A}>\tau_{B} \\
\frac{\left(1-\alpha_{B}\right)\left(2+\alpha_{A}+\alpha_{B}\right) c_{A}+\left(\alpha_{B}-\alpha_{A}\right) d_{A}+\left(2-\alpha_{A}^{2}-\alpha_{A} \alpha_{B}\right)\left(d_{B}-c_{T}\right)}{\left(2-\alpha_{A}-\alpha_{B}\right)\left(2+\alpha_{A}+\alpha_{B}\right)} & \text { for } & \tau_{A}<\tau_{B}
\end{array}\right.
$$

The optimal sales quantities under centralized production for $\tau_{A}>\tau_{B}$ are

$$
s_{A}^{*}=\frac{2\left(d_{A}-c_{A}\right)+\left(d_{B}-c_{A}-c_{T}\right)\left(\alpha_{A}+\alpha_{B} \frac{1-\tau_{B}}{1-\tau_{A}}\right)}{4-\left(\alpha_{A} \sqrt{\frac{1-\tau_{A}}{1-\tau_{B}}}+\alpha_{B} \sqrt{\frac{1-\tau_{B}}{1-\tau_{A}}}\right)^{2}}
$$


and

$$
s_{B}^{*}=\frac{2\left(d_{B}-c_{A}-c_{T}\right)+\left(d_{A}-c_{A}\right)\left(\alpha_{B}+\alpha_{A} \frac{1-\tau_{A}}{1-\tau_{B}}\right)}{4-\left(\alpha_{A} \sqrt{\frac{1-\tau_{A}}{1-\tau_{B}}}+\alpha_{B} \sqrt{\frac{1-\tau_{B}}{1-\tau_{A}}}\right)^{2}}
$$

The optimal sales quantities under centralized production and $\tau_{A}<\tau_{B}$ are

$$
s_{A}^{*}=\frac{2\left(d_{A}-c_{A}\right)+\left(d_{B}-c_{A}-c_{T}\right)\left(\alpha_{A}+\alpha_{B}\right)}{4-\left(\alpha_{A}+\alpha_{B}\right)^{2}}
$$

and

$$
s_{B}^{*}=\frac{2\left(d_{B}-c_{A}-c_{T}\right)+\left(d_{A}-c_{A}\right)\left(\alpha_{A}+\alpha_{B}\right)}{4-\left(\alpha_{A}+\alpha_{B}\right)^{2}}
$$

The optimal sales quantities under decentralized production are

$$
s_{A}^{*}=\frac{2\left(d_{A}-c_{A}\right)+\left(d_{B}-c_{B}\right)\left(\alpha_{A}+\alpha_{B} \frac{1-\tau_{B}}{1-\tau_{A}}\right)}{4-\left(\alpha_{A} \sqrt{\frac{1-\tau_{A}}{1-\tau_{B}}}+\alpha_{B} \sqrt{\frac{1-\tau_{B}}{1-\tau_{A}}}\right)^{2}}
$$

and

$$
s_{B}^{*}=\frac{2\left(d_{B}-c_{B}\right)+\left(d_{A}-c_{A}\right)\left(\alpha_{B}+\alpha_{A} \frac{1-\tau_{A}}{1-\tau_{B}}\right)}{4-\left(\alpha_{A} \sqrt{\frac{1-\tau_{A}}{1-\tau_{B}}}+\alpha_{B} \sqrt{\frac{1-\tau_{B}}{1-\tau_{A}}}\right)^{2}}
$$

Proof: See Appendix A.2.

For $\tau_{B}>\tau_{A}$, country $B$ realizes no tax revenues $\left(\mathcal{T}_{B}=0\right)$ under centralized production. In contrast, country $A$ generates strictly positive tax revenues $\left(\mathcal{T}_{A}>0\right)$.

The results in (26) show that the MNE also chooses a transfer price at the lower end (if $\tau_{A}>\tau_{B}$ ) or the upper end (if $\tau_{A}<\tau_{B}$ ) of the legally accepted interval if complementarities between national sales exist.

Next, we look at the optimal sales quantities under centralized production. Compared to the pre-tax case, the implementation of corporate taxation does not have an impact on $s_{A}^{*}$ and $s_{B}^{*}$ in both countries if $\tau_{A}<\tau_{B}$. In contrast, under $\tau_{A}>\tau_{B}$ the implementation of corporate taxation changes the optimal sales quantities in both countries. For simplicity reasons we again assume symmetric complementarities in both countries, $\alpha=\alpha_{A}=\alpha_{B}$. For the optimal sales quantity $s_{A}^{*}$ holds that it increases with the implementation of corporate taxation. ${ }^{11}$ The optimal sales quantity $s_{B}^{*}$ is higher under corporate taxation

\footnotetext{
${ }^{11}$ Under centralized production, the optimal after-tax sales quantity $s_{A}^{*}$ is higher than the pre-tax sales quantity under $\tau_{A}>\tau_{B}$ if the following condition holds: $\alpha_{B}<\frac{2 \sqrt{1+\tau_{A} \tau_{B}-\tau_{A}-\tau_{B}}}{2-\tau_{A}-\tau_{B}}$. Since $\frac{2 \sqrt{1+\tau_{A} \tau_{B}-\tau_{A}-\tau_{B}}}{2-\tau_{A}-\tau_{B}}>1$, this condition is always fulfilled.
} 
Figure 1: Comparison of optimal $s_{A}$ and $s_{B}$
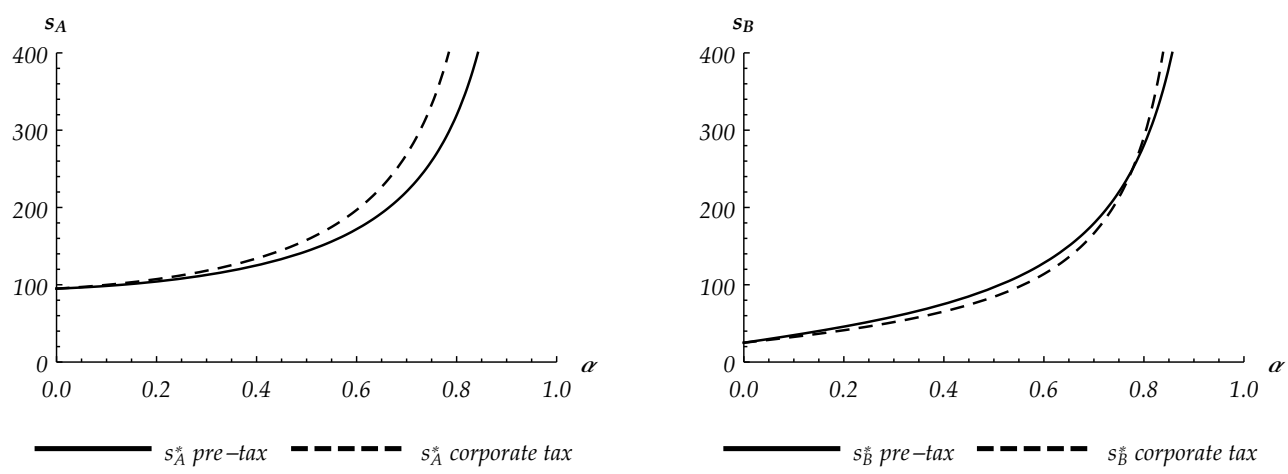

Panel A: Comparison of optimal $s_{A}$ and $s_{B}$ under central production and $\tau_{A}>\tau_{B}$
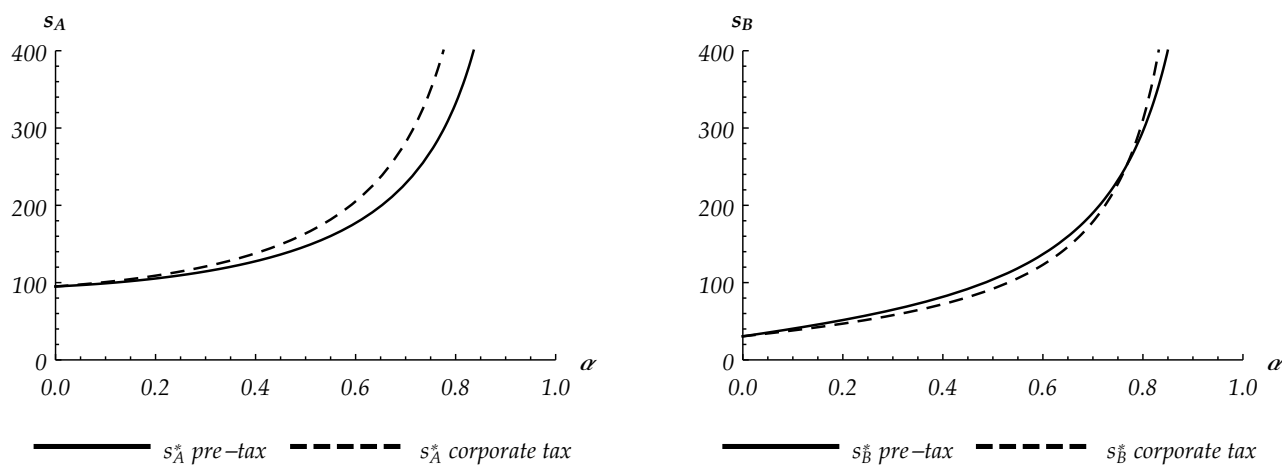

Panel B: Comparison of optimal $s_{A}$ and $s_{B}$ under decentral production and $\tau_{A}>\tau_{B}$

The figure illustrates the choice of the optimal sales quantities $s_{A}^{*}$ and $s_{B}^{*}$ contingent on $\alpha$. Panel A shows optimal sales quantities under central production and $\tau_{A}>\tau_{B}$. Panel $\mathrm{B}$ exhibits sales quantities under decentral production. Both panels are based on the following parameter assumptions: $d_{A}=200, d_{B}=80$, $c_{A}=10, c_{T}=20, \tau_{A}=0.5, \tau_{B}=0.01$. In addition, Panel $\mathrm{A}$ assumes that $c_{B} \geq 30$ which warrants central production. Panel B assumes $c_{B}=19$.

compared to the pre-tax regime if $\alpha$ exceeds a certain threshold. ${ }^{12}$ This threshold increases in $\tau_{B}, c_{T}, d_{A}$ and decreases in $d_{B}$. Thus, the after-tax sales quantity $s_{B}^{*}$ can (but does not have to) be higher than the pre-tax sales quantity if complementarities between national sales are high. Panel A of Figure 1 shows a numerical example for the optimal sales quantities $s_{A}^{*}$ and $s_{B}^{*}$ in the pre-tax and corporate tax regime in the centralized setting depending on $\alpha$.

\footnotetext{
${ }^{12}$ The exact threshold is provided in (93) in Appendix A.4.
} 
Under decentralized production, the implementation of taxation impacts the optimal sales quantities in both countries as well. In country $A$ the implementation of corporate taxation results always in a higher optimal sales quantity $s_{A}^{*}$ compared to the pretax case. $^{13}$ In country $B$ the optimal sales quantity $s_{B}^{*}$ always increases after the implementation of corporate taxes if $\tau_{A}<\tau_{B}$. For $\tau_{B}<\tau_{A}$, the optimal sales quantity $s_{B}^{*}$ under corporate taxation exceeds the one under the pre-tax regime if $\alpha$ meets a certain threshold. ${ }^{14}$ This threshold increases in $\tau_{B}, c_{B}, d_{A}$ and decreases in $c_{A}, d_{B}$. Panel B of Figure 1 provides a numerical example for the optimal sales quantities $s_{A}^{*}$ and $s_{B}^{*}$ in the pre-tax and corporate tax regime depending on $\alpha$ if decentralized production is chosen.

Finally, we look at the location decision of the MNE. (25) shows that this decision remains unaffected compared to the regime without taxes if $\tau_{A}>\tau_{B}$. To analyze the impact of taxation on the company's location decision if $\tau_{A}<\tau_{B}$ we compare the threshold for centralized production under corporate income taxation, $\widehat{c_{B}^{c}}$ (see (25)), with the pre-tax case, $\widehat{c_{B}}$ ( see (22)). We further assume symmetric complementarities in both countries, $\alpha=\alpha_{A}=\alpha_{B} .{ }^{15}$ We find that

$$
\begin{aligned}
& \widehat{c_{B}^{c}}-\widehat{c_{B}} \\
& =\frac{\alpha\left(2-\tau_{A}-\tau_{B}\right)\left(d_{A}-c_{A}\right)}{2\left(1-\tau_{B}\right)}+d_{B}-2 c_{A}-2 c_{T} \\
& +\frac{\sqrt{\frac{(1-\alpha)\left(4\left(1-\tau_{A}\right)\left(1-\tau_{B}\right)-\alpha^{2}\left(2-\tau_{A}-\tau_{B}\right)^{2}\right)}{1+\alpha}}\left((1+\alpha) c_{A}-\alpha d_{A}-d_{B}+c_{T}\right)}{2(1-\alpha)\left(1-\tau_{B}\right)}
\end{aligned}
$$

The threshold, that the production cost in country $B$ must exceed to trigger a centralized production, increases (decreases) compared to a pre-tax regime if (33) takes on a positive (negative) value. Contrary to our finding in the absence of complementarities (see (14)), the impact of corporate taxation on the threshold is not clear-cut. Figure 2 shows that it depends on different factors whether the threshold for $c_{B}$ increases or decreases compared to a pre-tax regime. While no or low complementarities in sales always lead to a lower $c_{B}$-threshold (and thus increased incentives for centralized production), the threshold may even increase if high complementarities in sales exist. ${ }^{16}$ Panel B shows that this effect is even stronger for low

\footnotetext{
${ }^{13}$ In the decentralized setting, the optimal after-tax sales quantity $s_{A}^{*}$ is higher than the pre-tax sales quantity if $\alpha_{B}<\frac{2 \sqrt{1+\tau_{A} \tau_{B}-\tau_{A}-\tau_{B}}}{2-\tau_{A}-\tau_{B}}$. This condition is always fulfilled, see $\mathrm{FN}^{11}$.

${ }^{14}$ The exact threshold is provided in (94) in Appendix A.4.

${ }^{15}$ This implies that the increase in customers' willingness to pay caused by a higher number of customers in the other country is independent from the customers' location (in country $A$ or $B$ ).

${ }^{16}$ Note that negative values for the $c_{B}$ - threshold under corporate taxation indicate that the MNE would prefer a centralized production even if production costs would be zero in country $B$ since the fiscal advantages from centralized production overcompensate the cost differences between both countries.
} 
Figure 2: Determinants of the $M N E^{\prime} s$ location decision

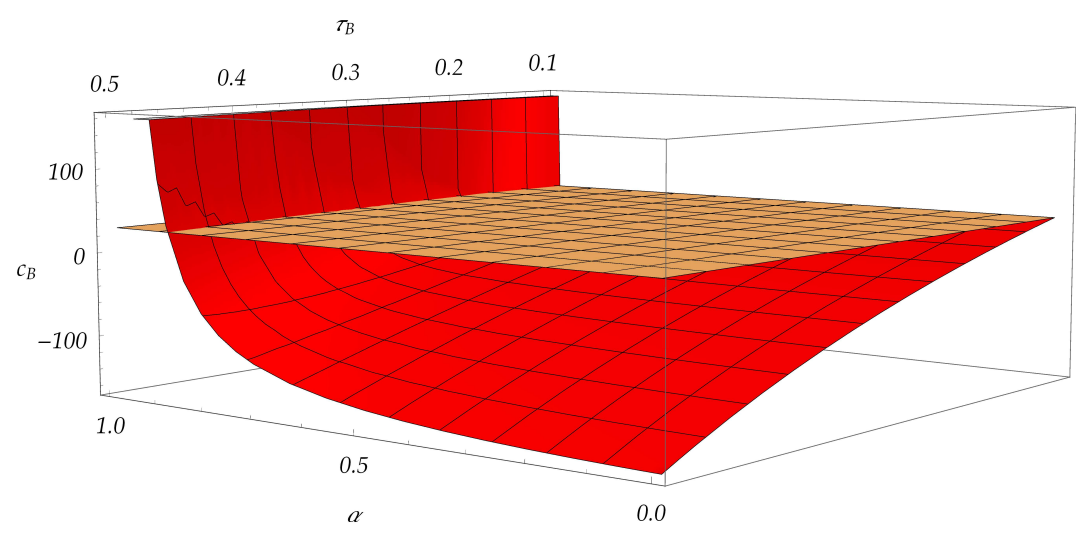

Panel A: The impact of taxes and complementarities in sales on firm location

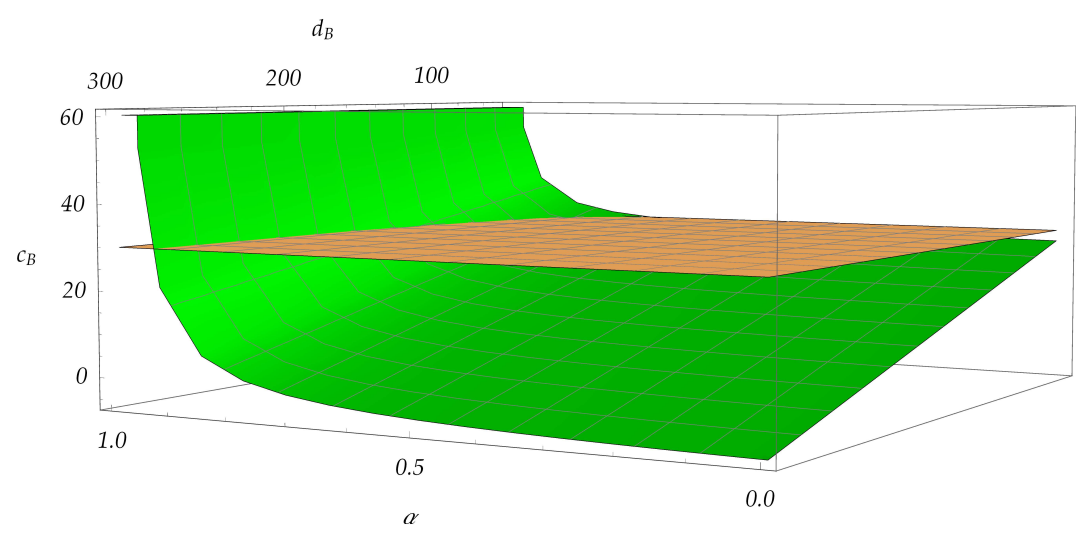

Panel B: The impact of market size and complementarities in sales on firm location

The figure illustrates the effect of different factors on the threshold for $c_{B}$ that has to be met to warrant centralized production. Both panels show thresholds under a pre-tax regime and under corporate taxation. Panel A shows the effect of varying complementarities in sales (with $\alpha=\alpha_{A}=\alpha_{B}$ ) and of a variation in the tax rate $\tau_{B}$ (for a constant value $\tau_{A}=0.1$ ) on the threshold for $c_{B}$. The red area refers to the threshold under corporate taxation, and the brown area refers to the threshold before tax. Panel B illustrates the impact of complementarities in sales and of the market size $d_{B}$. Here, the green area refers to the threshold under corporate taxation, and the brown area refers to the threshold before tax.

levels of $d_{B}$, that is, if the margin in country $B$ would be relatively low in the absence of complementarities. 


\subsection{Minimum taxation regime}

Lemma 6. If minimum taxation is feasible, let $d_{B} \leq \frac{\eta}{\theta} 17$ and $c_{B}>c_{A}+c_{T}$. Then, production is centralized.

The optimal transfer price $t^{*}$ is

$$
t^{*}=c_{A}
$$

The optimal sales quantities under centralized production are

$$
s_{A}^{*}=\frac{2\left(d_{A}-c_{A}\right)+\left(d_{B}-c_{A}-c_{T}\right)\left(\alpha_{A}+\alpha_{B} \frac{1-\tau_{B}}{1-\tau_{A}}\right)}{4-\left(\alpha_{A} \sqrt{\frac{1-\tau_{A}}{1-\tau_{B}}}+\alpha_{B} \sqrt{\frac{1-\tau_{B}}{1-\tau_{A}}}\right)^{2}}
$$

and

$$
s_{B}^{*}=\frac{2\left(d_{B}-c_{A}-c_{T}\right)+\left(d_{A}-c_{A}\right)\left(\alpha_{B}+\alpha_{A} \frac{1-\tau_{A}}{1-\tau_{B}}\right)}{4-\left(\alpha_{A} \sqrt{\frac{1-\tau_{A}}{1-\tau_{B}}}+\alpha_{B} \sqrt{\frac{1-\tau_{B}}{1-\tau_{A}}}\right)^{2}}
$$

For $d_{B} \leq \frac{\eta}{\theta}$ and $c_{B}<c_{A}+c_{T}$ decentralized production is optimal. The optimal sales quantities of Lemma 5 apply.

Proof: See Appendix A.5.

For $\tau_{A}>\tau_{B}$, the location decision of the MNE, $t^{*}$, and $s_{i}^{*}$ are not distorted. Thus, $\mathcal{T}_{A}$ and $\mathcal{T}_{B}$ remain the same compared to the corporate tax regime. For $\tau_{B}>\tau_{A}, \mathcal{T}_{B}$ increases due to the implementation of minimum taxation. Depending on the parameter setting $\mathcal{T}_{A}$ decreases or increases compared to the corporate tax regime. ${ }^{18}$

With regard to the location decision of the MNE, our previous result (see Lemma 3) based on the separability of sales is confirmed. Specifically, centralized production is chosen if $c_{B}>c_{A}+c_{T}$ as long as $d_{B}$ falls short of a certain threshold. ${ }^{19}$ Thus, minimum taxation reinstates the pre-tax cost threshold for the MNE's production decision. As described above, this means that the location decision of the $M N E$ is identical to the one under corporate taxation if $\tau_{A}>\tau_{B}$. If $\tau_{A}<\tau_{B}$ the incentives to choose a centralized or decentralized production process change compared to the corporate taxation regime. However, the direction of this change is not clear-cut and depends on different factors such as $d_{B}$ and $\alpha .^{20}$

\footnotetext{
${ }^{17}$ For the exact threshold see (95) in Appendix A.5.

${ }^{18}$ An illustration of this tax revenue effect is provided in Appendix A.6.

${ }^{19}$ Note, however, that the specific value of this threshold and therefore the likelihood of a unilateral application of minimum taxation changes.

${ }^{20}$ For $d_{B}>\frac{\eta}{\theta}$ the sales formula is applied by both countries under minimum taxation. For an analysis of a
} 
As for $\alpha=0$, a unilateral application of minimum taxation leads to a transfer price of $c_{A}$. If $\tau_{A}<\tau_{B}$, this implies a reduction of the transfer price from the upper to the lower end of the allowed continuum, i.e. from $p_{B}-c_{T}$ to $c_{A}$. However, considering complementarities in sales $\left(\alpha_{A}\right.$ and $\left.\alpha_{B}>0\right)$ we find that the implementation of minimum taxation not only leads to an adjustment of the transfer price but also changes optimal sales quantities for $\tau_{B}>\tau_{A}$. In case both countries determine taxable profits according to the sales formula, adjustments in sales occur as well.

\section{Discussion}

Our analysis shows that the implementation of a minimum taxation regime can have an impact on optimal sales quantities and on the production location of the $M N E$, but also on the transfer prices and tax revenues of both countries. Thereby, our results suggest that real effects of taxation depend on the characteristics of the product markets. Table 1 provides an overview of the findings.

Our results show for independent local demand, see section 2, that local sales remain unchanged - both under corporate taxation and under minimum taxation given unaltered location decisions. In contrast, when we allow for complementarities between national sales in section 3, optimal sales quantities are affected by the fiscal regime. For $\tau_{A}>\tau_{B}$, optimal sales quantities change under corporate taxation compared to a pretax regime. As shown in Figure 1 in section 3, the optimal sales quantity in country A, $s_{A}^{*}$, under corporate taxation exceeds the one of the pre-tax regime. The sales quantity in country $\mathrm{B}, s_{A}^{*}$, decreases or increases compared to the pre-tax regime, depending on the extent of the complementarities in sales and on further parameters, namely tax rates, transaction costs, and the size of the respective markets. Under minimum taxation, sales quantities remain the same compared to the corporate tax regime if $\tau_{A}>\tau_{B}$. If $\tau_{A}<\tau_{B}$, optimal sales quantities do not change under corporate taxation compared to the pretax regime. Under a minimum tax regime however, sales quantities in both countries are adjusted.

While taxation does not affect the location decision of the MNE as long as $\tau_{A}>\tau_{B}$, it changes incentives for centralized or decentralized production if $\tau_{A}<\tau_{B}$. Specifically, minimum taxation reinstates the cost parameter threshold from the pre-tax regime if $\tau_{A}<\tau_{B}$. Compared to the corporate tax regime this leads to a relocation of real activity in form of assets and labor from the low-tax country $A$ to the high-tax country $B$. In

complete tax base allocation via formula apportionment, which is beyond the scope of this paper, see, e.g. Martini et al. (2012). 
contrast, the effect of a corporate taxation regime depends on the characteristics of the product market. In the absence of complementarities, corporate taxation always provides incentives to centralize production in country $A$ (see section 2 ). For high complementarities in sales, corporate taxation can even provide incentives to produce decentrally, as illustrated by Figure 2 in section 3.2. ${ }^{21}$

Based on a simulation, Figure 3 illustrates how the MNE's location decision depends on the respective fiscal regime for $\tau_{A}<\tau_{B}$. In Panels $\mathrm{A}-\mathrm{C}$ a minimum tax rate of $15 \%$ in the low-tax country is applied. In each panel, the figure on the left assumes $\alpha=0$ and the figure on the right assumes $\alpha_{A}=\alpha_{B}=0.5$. The red areas indicate that decentralized production is optimal under all three fiscal regimes. The green areas indicate that decentralized production is optimal for the pre-tax and the minimum tax regime, while centralized production is optimal for the corporate tax regime. The blue areas suggest centralized production under all three fiscal regimes. Sections 2 and 3 allow for sales re-allocations due to a direct application of the sales formula by both countries. While a detailed analyses of the resulting optima is beyond the scope of this paper, the grey areas in Figure 3 indicate parameter settings where both countries would apply the sales formula under a minimum taxation setting.

\footnotetext{
${ }^{21}$ In these cases, a minimum taxation regime always entails an application of the sales formula by both countries. If an MNE chooses centralized production its after-tax profit under minimum taxation can never be higher than its after-tax profit under corporate taxation (if not, the MNE would have chosen this optimum under corporate taxation in the first place). Therefore, a minimum taxation regime will never make centralized production more attractive compared to decentralized production.
} 


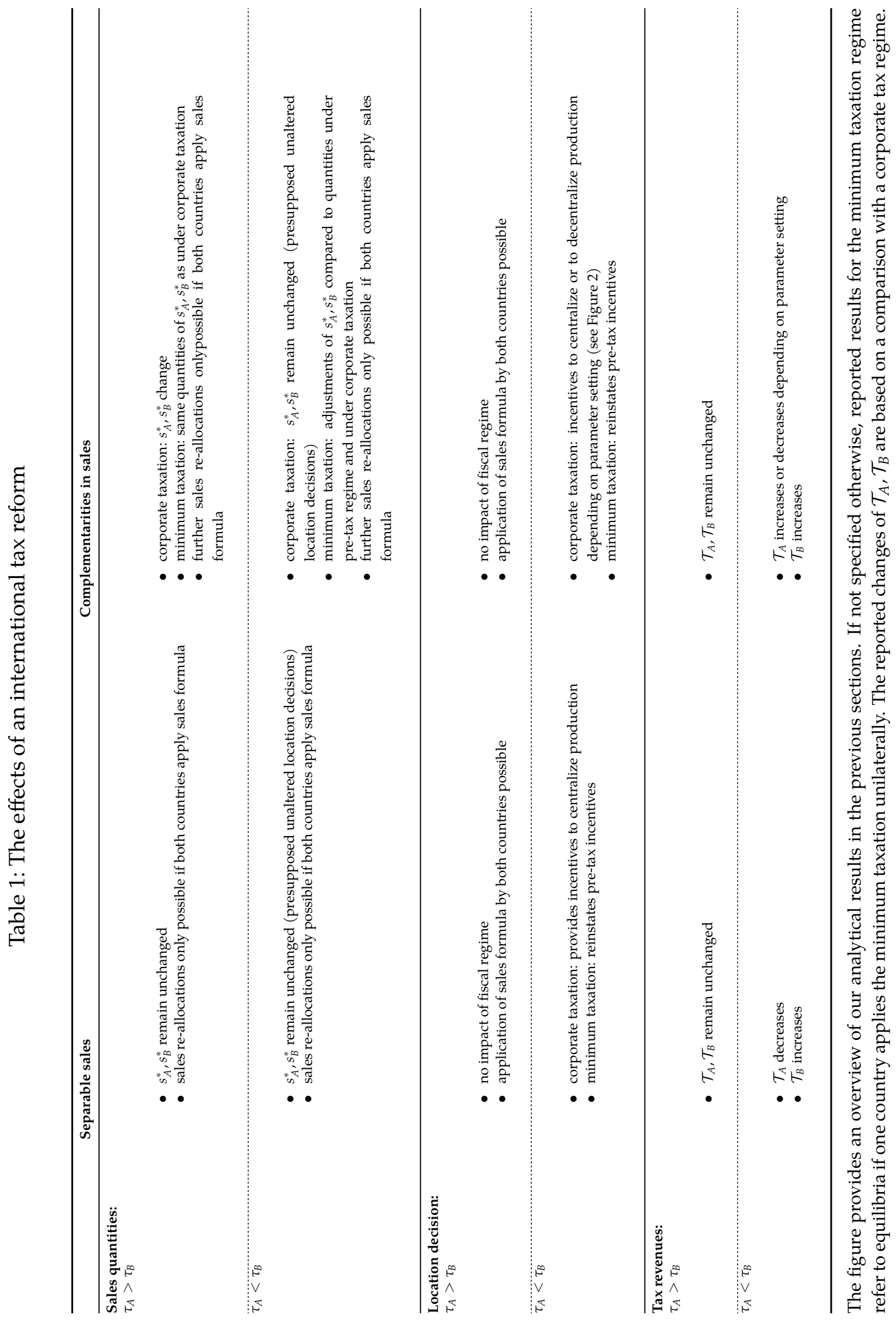


Panel A of Figure 3 shows that even for small tax rate differentials between country $A$ and $B$ a specific unit cost range in country $B$ (for a given cost parameter $c_{A}$ ) exists where a minimum tax regime changes the location decision of the MNE. Comparing Panels $\mathrm{A}$ and $\mathrm{B}$ confirms that this range increases the higher the tax rate differential between $A$ and $B$, and comparing Panels $C$ and $D$ reaffirms that not only the amount of the tax rate differential, but also the levels of the respective tax rates matter. For the demand functions assumed in sections 2 and 3 we also show that changes in the MNE's location decision after the introduction of a minimum taxation regime (as indicated by the green area) are more likely the greater the market size of country $B, d_{B}$. Comparing the left and the right figure in each panel illustrates that complementarities in sales affect the likelihood that both countries apply the sales formula if a minimum tax is feasible. This outcome which typically involves a change of the optimal sales quantities compared to the pre-tax setting is denoted by a grey area.

Finally, we analyze the impact of taxation on the tax revenues in both countries. Thereby, we investigate the difference between fiscal revenues under a corporate income tax and a minimum taxation regime. For $\tau_{A}>\tau_{B}$, the tax revenues in both countries remain unchanged. If $\tau_{A}<\tau_{B}$, the tax revenue for the high-tax country, $\mathcal{T}_{B}$, increases under minimum taxation for both types of product markets. In contrast, the tax revenue of the low-tax country, $\mathcal{T}_{A}$, decreases for traditional product markets, but might even increase under certain parameter settings if complementarities in sales exist. 
Figure 3: Location decisions under different fiscal regimes

Panel A: $\tau_{A}=0.15 ; \tau_{B}=0.16$

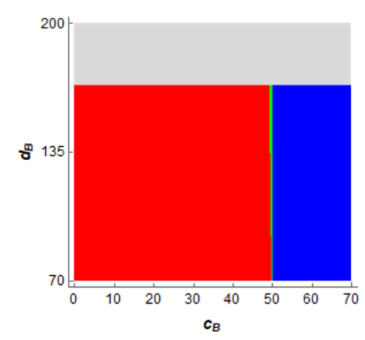

$\alpha_{A}=\alpha_{B}=0$

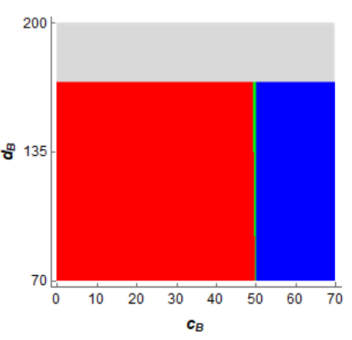

$\alpha_{A}=\alpha_{B}=0.5$

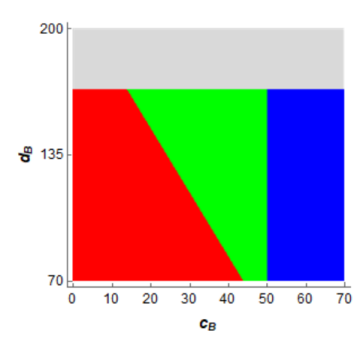

$\alpha_{A}=\alpha_{B}=0$

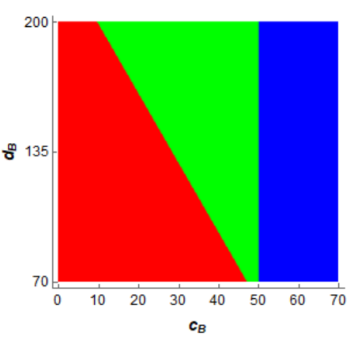

$\alpha_{A}=\alpha_{B}=0.5$

Panel C: $\tau_{A}=0.15 ; \tau_{B}=0.25$

Panel D: $\tau_{A}=0.4 ; \tau_{B}=0.5$
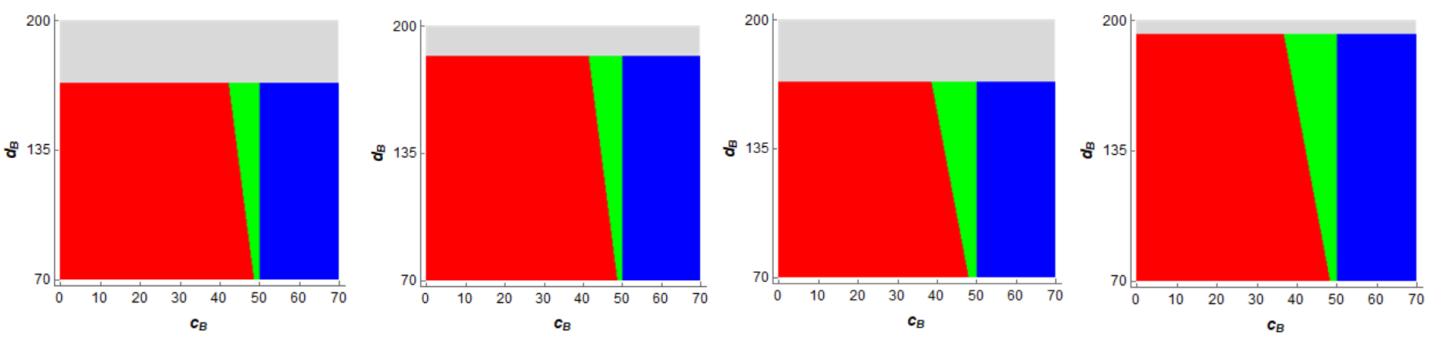

$$
\alpha_{A}=\alpha_{B}=0
$$

$\alpha_{A}=\alpha_{B}=0.5$

$\alpha_{A}=\alpha_{B}=0.5$

The figure provides an overview of the MNE's location decision under the three fiscal regimes. The red area indicates that decentralized production is optimal under all three fiscal regimes. The green area indicates that decentralized production is optimal for the pre-tax and the minimum tax regime, while centralized production is optimal for the corporate tax regime. The blue area suggests centralized production under all three fiscal regimes. The grey area indicates that both countries would apply the sales formula under a minimum taxation setting. In the simulations we use the following parameters: $d_{A}=135, c_{A}=40, c_{T}=10$ 


\section{Conclusion}

In this study we theoretically analyze an MNE's decision about the location of its production facilities, about its sales quantities, and about the transfer price in a twocountry setting. We compare a pre-tax regime, a common corporate taxation regime, and a minimum taxation regime. In the latter regime countries can unilaterally determine taxable income based on the distribution of sales. Moreover, we analyze different types of inverse demand functions: Firstly, we assume that national sales are fully separable and do not affect each other. Secondly, we allow for national sales acting as complements, which is typical for social network services. Hereby, an increase in sales in one country results in a higher sales price in the other country.

Our results show that the implementation of an international tax reform that includes new profit allocation rules as well as the introduction of minimum taxation triggers re-locations of production facilities. Regularly, minimum taxation restores the MNE's location decision from the pre-tax regime. Moreover, the fiscal regime affects optimal sales quantities for modern business models. Independently from the characteristics of the product market, the implementation of a minimum taxation regime causes the MNE to adjust the reported transfer price significantly compared to a corporate tax regime. Thus, besides impacting transfer prices an international tax reform affects real activities such as sales and production location. Whereas the tax revenue effect in the low-tax country depends on market characteristics, minimum taxation increases tax revenues in the high-tax country for both traditional and modern product markets.

The results of our study have to be interpreted against the background of the model assumptions. For instance, we base our analysis on a linear cost function without fixed costs. Moreover, our paper considers a sales formula as a means to determine the allocation of taxable income. In practice, different proposals to determine taxable income in an international tax reform are currently discussed. Nevertheless, our study provides fundamental insights about the real effects of an international tax reform. Policy makers should consider these insights in the development of a future international minimum tax regime.

Our study also provides a theoretical basis for future empirical studies on the real effects of minimum taxation. For example, empirical analyses could test whether the implementation of a minimum taxation regime actually leads to more decentralized production structures. Moreover, they could investigate the impact of product market characteristics on the development of fiscal revenues. 


\section{A. Proofs}

\section{A.1. Proof of Lemmas 1 and 4}

We start with determining optimal sales quantities, $s_{A}^{*}$ and $s_{B}^{*}$, under both a) centralized and $b$ ) decentralized production. We then c) compare the resulting profits and determine the threshold for centralized production.

a) With centralized production, i.e, $x_{A}=s_{A}+s_{B}$ and $q_{B}=s_{B}$, the total profit function (20) simplifies to:

$$
\Pi^{n o, c o}\left(s_{A}, s_{B}\right)=\left(d_{A}-s_{A}+\alpha_{A} s_{B}\right) s_{A}-c_{A}\left(s_{A}+s_{B}\right)+\left(d_{B}-s_{B}+\alpha_{B} s_{A}\right) s_{B}-c_{T} s_{B}
$$

Equalizing the first partial derivatives of (37) to zero gives:

$$
\begin{aligned}
\frac{\delta \Pi^{n o, c o}(\cdot)}{\delta s_{A}} & =d_{A}-c_{A}-2 s_{A}+\alpha_{A} s_{B}+\alpha_{B} s_{B}=0 \\
& \Leftrightarrow s_{A}=\frac{1}{2}\left[d_{A}-c_{A}+s_{B}\left(\alpha_{A}+\alpha_{B}\right)\right]
\end{aligned}
$$

and

$$
\begin{aligned}
\frac{\delta \Pi^{n o, c o}(\cdot)}{\delta s_{B}} & =d_{B}-c_{A}-c_{T}-2 s_{B}+\alpha_{A} s_{A}+\alpha_{B} s_{A}=0 \\
& \Leftrightarrow s_{B}=\frac{1}{2}\left[d_{B}-c_{A}-c_{T}+s_{A}\left(\alpha_{A} s_{A}+\alpha_{B}\right)\right]
\end{aligned}
$$

Simultaneously solving (38) and (39) gives the optimal sales quantities $s_{A}^{*}$ and $s_{B}^{*}$ :

$$
\begin{aligned}
& s_{A}^{*}=\frac{2\left(d_{A}-c_{A}\right)+\left(d_{B}-c_{A}-c_{T}\right)\left(\alpha_{A}+\alpha_{B}\right)}{4-\left(\alpha_{A}+\alpha_{B}\right)^{2}} \\
& s_{B}^{*}=\frac{2\left(d_{B}-c_{A}-c_{T}\right)+\left(d_{A}-c_{A}\right)\left(\alpha_{A}+\alpha_{B}\right)}{4-\left(\alpha_{A}+\alpha_{B}\right)^{2}}
\end{aligned}
$$

(40) and (41) display maximizers as can be inferred from the Hessian. It is negative definite indicating a strictly concave function.

$$
H\left(s_{A}, s_{B}\right)=\left(\begin{array}{cc}
\frac{\delta^{2} \Pi^{n o}(\cdot)}{\delta s_{A}^{2}} & \frac{\delta^{2} \Pi^{n o}(\cdot)}{\delta s_{A} \delta s_{B}} \\
\frac{\delta^{2} \Pi^{n o}(\cdot)}{\delta s_{A} \delta s_{B}} & \frac{\delta^{2} \Pi^{n o}(\cdot)}{\delta s_{B}^{2}}
\end{array}\right)=\left(\begin{array}{cc}
-2 & \alpha_{A}+\alpha_{B} \\
\alpha_{A}+\alpha_{B} & -2
\end{array}\right)
$$


b) Under decentralized production, i.e., $x_{i}=s_{i} \forall i$, the total profit function (20) becomes:

$$
\Pi^{n o, c o}(\cdot)=\left(d_{A}-s_{A}+\alpha_{A} s_{B}-c_{A}\right) s_{A}+\left(d_{B}-s_{B}+\alpha_{B} s_{A}-c_{B}\right) s_{B}
$$

Equalizing the first partial derivatives of (43) to zero yields:

$$
\begin{aligned}
\frac{\delta \Pi^{n o, c o}(\cdot)}{\delta s_{A}} & =d_{A}-c_{A}-2 s_{A}+\alpha_{A} s_{B}+\alpha_{B} s_{B}=0 \\
& \Leftrightarrow s_{A}=\frac{1}{2}\left[d_{A}-c_{A}+s_{B}\left(\alpha_{A}+\alpha_{B}\right)\right] \\
\frac{\delta \Pi^{n o, c o}(\cdot)}{\delta s_{B}} & =d_{B}-c_{B}-2 s_{B}+\alpha_{A} s_{A}+\alpha_{B} s_{A}=0 \\
& \Leftrightarrow s_{B}=\frac{1}{2}\left[d_{B}-c_{B}+s_{A}\left(\alpha_{A}+\alpha_{B}\right)\right]
\end{aligned}
$$

Simultaneously solving (44) and (45) yields the optimal sales quantities $s_{A}^{*}$ and $s_{B}^{*}$ :

$$
\begin{aligned}
& s_{A}^{*}=\frac{2\left(d_{A}-c_{A}\right)+\left(d_{B}-c_{B}\right)\left(\alpha_{A}+\alpha_{B}\right)}{4-\left(\alpha_{A}+\alpha_{B}\right)^{2}} \\
& s_{B}^{*}=\frac{2\left(d_{B}-c_{B}\right)+\left(d_{A}-c_{A}\right)\left(\alpha_{A}+\alpha_{B}\right)}{4-\left(\alpha_{A}+\alpha_{B}\right)^{2}}
\end{aligned}
$$

(46) and (47) display maximizers as the Hessian is negative definite.

$$
H\left(s_{A}, s_{B}\right)=\left(\begin{array}{cc}
-2 & \alpha_{A}+\alpha_{B} \\
\alpha_{A}+\alpha_{B} & -2
\end{array}\right)
$$

c) To determine the threshold $c_{B}$ that has to be exceeded to warrant a centralized production we compare the resulting profits under centralized and decentralized production. $^{22}$ For this comparison, let $s_{A, c}^{*} s_{B, c}^{*}$ denote optimal sales quantities under centralized production and $s_{A, d}^{*} s_{B, d}^{*}$ optimal sales quantities under

\footnotetext{
${ }^{22}$ We assume that production is decentralized if $c_{B}=c_{A}+c_{T}$.
} 
decentralized production. Then, centralized production requires

$$
\begin{aligned}
& \left(d_{A}-s_{A, c}^{*}+\alpha_{A} s_{B, c}^{*}\right) s_{A, c}^{*}-c_{A}\left(s_{A, c}^{*}+s_{B, c}^{*}\right)+\left(d_{B}-s_{B, c}^{*}+\alpha_{B} s_{A, c}^{*}\right) s_{B, c}^{*}-c_{T} s_{B, c}^{*} \\
& >\left(d_{A}-s_{A, d}^{*}+\alpha_{A} s_{B, d}^{*}-c_{A}\right) s_{A, d}^{*}+\left(d_{B}-s_{B, d}^{*}+\alpha_{B} s_{A, d}^{*}-c_{B}\right) s_{B, d}^{*}
\end{aligned}
$$

Solving for $c_{B}$ yields

$$
\begin{gathered}
c_{B}>\frac{\left(d_{A}-s_{A, d}^{*}+\alpha_{A} s_{B, d}^{*}-c_{A}\right) s_{A, d}^{*}+\left(d_{B}-s_{B, d}^{*}+\alpha_{B} s_{A, d}^{*}\right)}{s_{B, d}^{*}} \\
-\frac{\left(d_{A}-s_{A, c}^{*}+\alpha_{A} s_{B, c}^{*}-c_{A}\right) s_{A, c}^{*}+\left(d_{B}-s_{B, c}^{*}+\alpha_{B} s_{A, c}^{*}-c_{A}-c_{T}\right) s_{B, c}^{*}}{s_{B, d}^{*}}
\end{gathered}
$$

Replacing $s_{A, c}^{*}$ and $s_{B, c}^{*}$ with the optimal sales quantities from (40) and (41), and $s_{A, d}^{*}$ and $s_{B, d}^{*}$ with the optimal sales quantities from (46) and (47) yields the threshold that must be met to warrant centralized production:

$$
c_{B}>c_{A}+c_{T}
$$

\section{A.2. Proof of Lemmas 2 and 5}

We start with determining the optimal transfer price, $t^{*}$, occurring under centralized production. The first partial derivative of the total profit function, (21), with respect to the transfer price $t$ yields

$$
\frac{\delta \Pi^{\operatorname{tax}, c o}(\cdot)}{\delta t}=q_{B}\left(\tau_{B}-\tau_{A}\right)
$$

(52) indicates that the $M N E^{\prime} s$ after-tax profit is strictly increasing (decreasing) in $t$ if $\tau_{B}>(<) \tau_{A} \cdot{ }^{23}$ Thus, the MNE always chooses a transfer price $t^{*}$ at the upper (lower) end of the interval that is accepted by the fiscal authorities.

$$
t^{*}=\left\{\begin{array}{cc}
c_{A} & \text { for } \tau_{A}>\tau_{B} \\
p_{B}^{*}\left(s_{B}^{*}\right)-c_{T}=d_{B}-s_{B}^{*}+\alpha_{B} s_{A}^{*}-c_{T} & \text { for } \tau_{A}<\tau_{B}
\end{array}\right.
$$

Thereby, $p_{B}^{*}\left(s_{B}^{*}\right)$ and $s_{B}^{*}$ indicate the optimal sales price and the optimal sales quantity in country $B . t^{*}$ depending on the relation between $\tau_{A}$ and $\tau_{B}$ shows that the MNE engages in profit shifting.

\footnotetext{
${ }^{23}$ We do not consider the case of $\tau_{B}=\tau_{A}$ since no fiscal incentives for profit shifting would exist.
} 
Since the optimal transfer price $t^{*}$ in (53) depends on the relation of tax rates, we distinguish 1.) $\tau_{A}>\tau_{B}$ and 2.) $\tau_{A}<\tau_{B}$. Within these cases we further distinguish a) centralized and $b$ ) decentralized production.

1. Let $\tau_{A}>\tau_{B}$, then the optimal transfer price becomes $c_{A}$ under centralized production.

a) Assume centralized production, i.e., $x_{A}=s_{A}+s_{B}$ and $q_{B}=s_{B}$. The total profit function (21) becomes:

$$
\begin{aligned}
\Pi^{\operatorname{tax}, c o}\left(s_{A}, s_{B}\right) & =s_{A}\left(d_{A}-s_{A}+\alpha_{A} s_{B}-c_{A}\right)\left(1-\tau_{A}\right) \\
& +s_{B}\left(d_{B}-s_{B}+\alpha_{B} s_{A}-c_{A}-c_{T}\right)\left(1-\tau_{B}\right)
\end{aligned}
$$

Equalizing the partial derivatives of (54) to zero gives:

$$
\begin{aligned}
\frac{\delta \Pi^{\operatorname{tax}, c o}(\cdot)}{\delta s_{A}} & =\left(d_{A}-2 s_{A}+\alpha_{A} s_{B}-c_{A}\right)\left(1-\tau_{A}\right)+\alpha_{B} s_{B}\left(1-\tau_{B}\right)=0 \\
& \Leftrightarrow s_{A}=\frac{1}{2}\left[d_{A}-c_{A}+s_{B}\left(\alpha_{A}+\alpha_{B} \frac{1-\tau_{B}}{1-\tau_{A}}\right)\right] \\
\frac{\delta \Pi^{\operatorname{tax}, c o}(\cdot)}{\delta s_{B}} & =\alpha_{A} s_{A}\left(1-\tau_{A}\right)+\left(d_{B}+\alpha_{B} s_{A}-2 s_{B}-c_{A}-c_{T}\right)\left(1-\tau_{B}\right)=0 \\
& \Leftrightarrow s_{B}=\frac{1}{2}\left[d_{B}-c_{A}-c_{T}+s_{A}\left(\alpha_{B}+\alpha_{A} \frac{1-\tau_{A}}{1-\tau_{B}}\right)\right]
\end{aligned}
$$

Simultaneously solving (55) and (56) yields:

$$
s_{A}^{*}=\frac{2\left(d_{A}-c_{A}\right)+\left(d_{B}-c_{A}-c_{T}\right)\left(\alpha_{A}+\alpha_{B} \frac{1-\tau_{B}}{1-\tau_{A}}\right)}{4-\left(\alpha_{A} \sqrt{\frac{1-\tau_{A}}{1-\tau_{B}}}+\alpha_{B} \sqrt{\frac{1-\tau_{B}}{1-\tau_{A}}}\right)^{2}}
$$

and

$$
s_{B}^{*}=\frac{2\left(d_{B}-c_{A}-c_{T}\right)+\left(d_{A}-c_{A}\right)\left(\alpha_{B}+\alpha_{A} \frac{1-\tau_{A}}{1-\tau_{B}}\right)}{4-\left(\alpha_{A} \sqrt{\frac{1-\tau_{A}}{1-\tau_{B}}}+\alpha_{B} \sqrt{\frac{1-\tau_{B}}{1-\tau_{A}}}\right)^{2}}
$$

(57) and (58) display maximizers as the Hessian is negative definite. That is 
the case for all reasonable tax rate combinations of $\tau_{A}$ and $\tau_{B}$ :

$$
H\left(s_{A}, s_{B}\right)=\left(\begin{array}{cc}
-2\left(1-\tau_{A}\right) & \alpha_{A}\left(1-\tau_{A}\right)+\alpha_{B}\left(1-\tau_{B}\right) \\
\alpha_{A}\left(1-\tau_{A}\right)+\alpha_{B}\left(1-\tau_{B}\right) & -2\left(1-\tau_{B}\right)
\end{array}\right)
$$

b) Assume decentralized production, i.e., $x_{i}=s_{i}, \forall i$ and $q_{B}=0$, then the total profit function (21) becomes:

$$
\begin{aligned}
\Pi^{\operatorname{tax}, c o}\left(s_{A}, s_{B}\right) & =\left(s_{A}\left(d_{A}-s_{A}+\alpha_{A} s_{B}\right)-c_{A} s_{A}\right)\left(1-\tau_{A}\right) \\
& +\left(s_{B}\left(d_{B}-s_{B}+\alpha_{B} s_{A}\right)-c_{B} s_{B}\right)\left(1-\tau_{B}\right)
\end{aligned}
$$

Equalizing the first partial derivatives of (60) to zero yields:

$$
\begin{aligned}
\frac{\delta \Pi^{\operatorname{tax}, c o}(\cdot)}{\delta s_{A}} & =\left(d_{A}-2 s_{A}+\alpha_{A} s_{B}-c_{A}\right)\left(1-\tau_{A}\right)+\alpha_{B} s_{B}\left(1-\tau_{B}\right)=0 \\
& \Leftrightarrow s_{A}=\frac{1}{2}\left[d_{A}-c_{A}+s_{B}\left(\alpha_{A}+\alpha_{B} \frac{1-\tau_{B}}{1-\tau_{A}}\right)\right] \\
\frac{\delta \Pi^{\operatorname{tax}}(\cdot)}{\delta s_{B}} & =\alpha_{A} s_{A}\left(1-\tau_{A}\right)+\left(d_{B}-2 s_{B} \alpha_{B} s_{A}-c_{B}\right)\left(1-\tau_{B}\right)=0 \\
& \Leftrightarrow s_{B}=\frac{1}{2}\left[d_{B}-c_{B}+s_{A}\left(\alpha_{B}+\alpha_{A} \frac{1-\tau_{A}}{1-\tau_{B}}\right)\right]
\end{aligned}
$$

Inserting (61) and (62) in each other yields the optimal sales quantities. For $s_{A}^{*}$ it holds:

$$
s_{A}^{*}=\frac{2\left(d_{A}-c_{A}\right)+\left(d_{B}-c_{B}\right)\left(\alpha_{A}+\alpha_{B} \frac{1-\tau_{B}}{1-\tau_{A}}\right)}{4-\left(\alpha_{A} \sqrt{\frac{1-\tau_{A}}{1-\tau_{B}}}+\alpha_{B} \sqrt{\frac{1-\tau_{B}}{1-\tau_{A}}}\right)^{2}}
$$

For $s_{B}^{*}$ it holds:

$$
s_{B}^{*}=\frac{2\left(d_{B}-c_{B}\right)+\left(d_{A}-c_{A}\right)\left(\alpha_{B}+\alpha_{A} \frac{1-\tau_{A}}{1-\tau_{B}}\right)}{4-\left(\alpha_{A} \sqrt{\frac{1-\tau_{A}}{1-\tau_{B}}}+\alpha_{B} \sqrt{\frac{1-\tau_{B}}{1-\tau_{A}}}\right)^{2}}
$$

The Hessian is identical to case $1 a$.

c) Finally, comparing the resulting profits under centralized and decentralized production we determine the threshold that $c_{B}$ has to exceed under corporate 
taxation to warrant a centralized production process. Analogously to Appendix A.1, let $s_{A, c}^{*} s_{B, c}^{*}$ denote optimal sales quantities under centralized production and $s_{A, d}^{*}, s_{B, d}^{*}$ optimal sales quantities under decentralized production. Then, centralized production requires

$$
\begin{aligned}
& {\left[\left(d_{A}-s_{A, c}^{*}+\alpha_{A} s_{B, c}^{*}\right) s_{A, c}^{*}-c_{A}\left(s_{A, c}^{*}+s_{B, c}^{*}\right)+c_{A} s_{B, c}^{*}\right]\left(1-\tau_{A}\right)} \\
& +\left[\left(d_{B}-s_{B, c}^{*}+\alpha_{B} s_{A, c}^{*}\right) s_{B, c}^{*}-c_{A} s_{B, c}^{*}-c_{T} s_{B, c}^{*}\right]\left(1-\tau_{B}\right) \\
& >\left(d_{A}-s_{A, d}^{*}+\alpha_{A} s_{B, d}^{*}-c_{A}\right) s_{A, d}^{*}\left(1-\tau_{A}\right) \\
& +\left(d_{B}-s_{B, d}^{*}+\alpha_{B} s_{A, d}^{*}-c_{B}\right) s_{B, d}^{*}\left(1-\tau_{B}\right)
\end{aligned}
$$

Solving for $c_{B}$ yields

$$
\begin{gathered}
c_{B}>\frac{\left(d_{A}-s_{A, d}^{*}+\alpha_{A} s_{B, d}^{*}-c_{A}\right) s_{A, d}^{*}\left(1-\tau_{A}\right)}{s_{B, d}^{*}\left(1-\tau_{B}\right)}+\left(d_{B}-s_{B, d}^{*}+\alpha_{B} s_{A, d}^{*}\right) \\
-\frac{\left(d_{A}-s_{A, c}^{*}+\alpha_{A} s_{B, c}^{*}-c_{A}\right) s_{A, c}^{*}\left(1-\tau_{A}\right)}{s_{B, d}^{*}\left(1-\tau_{B}\right)} \\
-\frac{\left(d_{B}-s_{B, c}^{*}+\alpha_{B} s_{A, c}^{*}-c_{A}-c_{T}\right) s_{B, c}^{*}}{s_{B, d}^{*}}
\end{gathered}
$$

Replacing $s_{A, c}^{*}$ and $s_{B, c}^{*}$ with the optimal sales quantities from (57) and (58), and $s_{A, d}^{*}$ and $s_{B, d}^{*}$ with the optimal sales quantities from (63) and (64) we find that centralized production is beneficial whenever

$$
c_{B}>c_{A}+c_{T}
$$

2. Let $\tau_{A}<\tau_{B}$, implying that the optimal transfer price (53) becomes $t^{*}=p_{B}^{*}\left(s_{B}^{*}\right)-$ $c_{T}$ whenever production is centralized.

a) Assume centralized production, then inserting $t^{*}=p_{B}^{*}\left(s_{B}^{*}\right)-c_{T}$ and $x_{A}=$ $s_{A}+s_{B}$ into (21) yields:

$$
\begin{aligned}
\Pi^{\operatorname{tax}, c o}\left(s_{A}, s_{B}\right) & =\left[p_{A} s_{A}+\left(p_{B}^{*}\left(s_{B}^{*}\right)-c_{T}\right) s_{B}-c_{A}\left(s_{A}+s_{B}\right)\right]\left(1-\tau_{A}\right) \\
& +\left[d_{B} s_{B}-\left(p_{B}^{*}\left(s_{B}^{*}\right)-c_{T}\right) s_{B}-c_{T} s_{B}\right]\left(1-\tau_{B}\right) \\
& =\left(\left(d_{A}-s_{A}+\alpha_{A} s_{B}\right) s_{A}\right)\left(1-\tau_{A}\right) \\
& +\left[\left(d_{B}-s_{B}-c_{T}+\alpha_{B} s_{A}\right) s_{B}-c_{A}\left(s_{A}+s_{B}\right)\right]\left(1-\tau_{B}\right)
\end{aligned}
$$


The partial derivatives of (68) with respect to $s_{A}$ and $s_{B}$ are:

$$
\begin{gathered}
\frac{\delta \Pi^{t a x, c o}}{\delta s_{A}}=\left(d_{A}-2 s_{A}+\alpha_{A} s_{B}+\alpha_{B} s_{B}-c_{A}\right)\left(1-\tau_{A}\right)=0 \\
\Leftrightarrow s_{A}=\frac{1}{2}\left[d_{A}-c_{A}+s_{B}\left(\alpha_{A}+\alpha_{B}\right)\right] \\
\frac{\delta \Pi^{t a x, c o}}{\delta s_{B}}=\left(\alpha_{A} s_{A}+\alpha_{B} s_{A}+d_{B}-2 s_{B}-c_{A}-c_{T}\right)\left(1-\tau_{A}\right)=0 \\
\Leftrightarrow s_{B}=\frac{1}{2}\left[d_{B}-c_{A}-c_{T}+s_{A}\left(\alpha_{A}+\alpha_{B}\right)\right]
\end{gathered}
$$

Simultaneously solving (69) and (70) and yields:

$$
\begin{aligned}
& s_{A}^{*}=\frac{2\left(d_{A}-c_{A}\right)+\left(d_{B}-c_{A}-c_{T}\right)\left(\alpha_{A}+\alpha_{B}\right)}{4-\left(\alpha_{A}+\alpha_{B}\right)^{2}}, \\
& s_{B}^{*}=\frac{2\left(d_{B}-c_{A}-c_{T}\right)+\left(d_{A}-c_{A}\right)\left(\alpha_{A}+\alpha_{B}\right)}{4-\left(\alpha_{A}+\alpha_{B}\right)^{2}} .
\end{aligned}
$$

Thus, $p_{B}^{*}\left(s_{B}^{*}\right)$ equals:

$$
\begin{aligned}
& p_{B}^{*}\left(s_{B}^{*}\right)= \\
& \frac{2\left[d_{B}+c_{A}+c_{T}\right]-\left(\alpha_{A}-\alpha_{B}\right)\left(d_{A}-c_{A}\right)-\left(\alpha_{A}+\alpha_{B}\right)\left[\alpha_{A} d_{B}+\alpha_{B}\left(c_{A}+c_{T}\right)\right]}{4-\left(\alpha_{A}+\alpha_{B}\right)^{2}}
\end{aligned}
$$

The Hessian remains the same as in $1 a$.

b) For a decentralized production calculations and results from $1 b$ hold.

c) As for the setting with $\tau_{A}>\tau_{B}$, we finally compare the resulting profits under centralized and decentralized production to determine the threshold for $c_{B}$. Again, let $s_{A, c^{\prime}}^{*} s_{B, c}^{*}$ denote optimal sales quantities under centralized production and $s_{A, d}^{*}, s_{B, d}^{*}$ optimal sales quantities under decentralized production. Then, for $\tau_{A}<\tau_{B}$ centralized production requires

$$
\begin{aligned}
& {\left[\left(d_{A}-s_{A, c}^{*}+\alpha_{A} s_{B, c}^{*}-c_{A}\right) s_{A, c}^{*}+\left(d_{B}-s_{B, c}^{*}+\alpha_{B} s_{A, c}^{*}-c_{T}-c_{A}\right) s_{B, c}^{*}\right]\left(1-\tau_{A}\right)} \\
& >\left(d_{A}-s_{A, d}^{*}+\alpha_{A} s_{B, d}^{*}-c_{A}\right) s_{A, d}^{*}\left(1-\tau_{A}\right) \\
& +\left(d_{B}-s_{B, d}^{*}+\alpha_{B} s_{A, d}^{*}-c_{B}\right) s_{B, d}^{*}\left(1-\tau_{B}\right)
\end{aligned}
$$


Solving for $c_{B}$ yields

$$
\begin{aligned}
& c_{B}>\frac{\left(d_{A}-s_{A, d}^{*}+\alpha_{A} s_{B, d}^{*}-c_{A}\right) s_{A, d}^{*}\left(1-\tau_{A}\right)}{s_{B, d}^{*}\left(1-\tau_{B}\right)}+\left(d_{B}-s_{B, d}^{*}+\alpha_{B} s_{A, d}^{*}-c_{A}-c_{T}\right) \\
& -\frac{\left(d_{A}-s_{A, c}^{*}+\alpha_{A} s_{B, c}^{*}-c_{A}\right) s_{A, c}^{*}\left(1-\tau_{A}\right)}{s_{B, d}^{*}\left(1-\tau_{B}\right)} \\
& -\frac{\left(d_{B}-s_{B, c}^{*}+\alpha_{B} s_{A, c}^{*}-c_{T}-c_{A}\right) s_{B, c}^{*}\left(1-\tau_{A}\right)}{s_{B, d}^{*}\left(1-\tau_{B}\right)}
\end{aligned}
$$

Replacing $s_{A, c}^{*}$ and $s_{B, c}^{*}$ with the optimal sales quantities from (71) and (72), and $s_{A, d}^{*}$ and $s_{B, d}^{*}$ with the optimal sales quantities from (63) and (64) we find that centralized production is beneficial whenever

$$
\begin{aligned}
c_{B} & >\frac{1}{2}\left(d_{A}-c_{A}\right)\left(\alpha_{A} \frac{1-\tau_{A}}{1-\tau_{B}}+\alpha_{B}\right)+d_{B} \\
& -\omega\left[2\left(d_{B}-c_{A}-c_{T}\right)+\left(\alpha_{A}+\alpha_{B}\right)\left(d_{A}-c_{A}\right)\right]
\end{aligned}
$$

with

$$
\omega=\frac{\sqrt{\left(4-2 \alpha_{A} \alpha_{B}\right)\left(1-\tau_{A}\right)\left(1-\tau_{B}\right)-\alpha_{A}^{2}\left(1-\tau_{A}\right)^{2}-\alpha_{B}^{2}\left(1-\tau_{B}\right)^{2}}}{2 \sqrt{2-\alpha_{A}-\alpha_{B}} \sqrt{2+\alpha_{A}+\alpha_{B}}\left(1-\tau_{B}\right)}
$$

Since

$$
\begin{aligned}
& \omega\left[2\left(d_{B}-c_{A}-c_{T}\right)+\left(\alpha_{A}+\alpha_{B}\right)\left(d_{A}-c_{A}\right)\right] \\
& =s_{B}^{*} \frac{2 \sqrt{4-\left(\alpha_{A}+\alpha_{B}\right)^{2}}}{\left(1-\tau_{B}\right)} * \sqrt{\left(4-2 \alpha_{A} \alpha_{B}\right)\left(1-\tau_{A}\right)\left(1-\tau_{B}\right)-\alpha_{A}^{2}\left(1-\tau_{A}\right)^{2}-\alpha_{B}^{2}\left(1-\tau_{B}\right)^{2}}
\end{aligned}
$$

(25) follows.

For centralized production, tax revenues $\mathcal{T}_{A}$ in country $A$ and $\mathcal{T}_{B}$ in country $B$ are calculated by inserting optimal transfer prices and sales for the considered tax scenarios in $\mathcal{T}_{A}=\tau_{A}\left(p_{A} s_{A}+t s_{B}-c_{A}\left(s_{A}+s_{B}\right)\right)$ and $\mathcal{T}_{B}=\tau_{B} s_{B}\left(p_{B}-c_{T}-t\right)$. For decentralized production, tax revenues are calculated by inserting optimal sales into $\mathcal{T}_{A}=\tau_{A} s_{A}\left(p_{A}-c_{A}\right)$ and $\mathcal{T}_{B}=\tau_{B} s_{B}\left(p_{B}-c_{B}\right)$. 


\section{A.3. Proof of Lemma 3}

As seen before, minimum taxation applies only if production is centralized. Since minimum taxation is only applied if the reported profits in one country fall short of the taxable profit according to the formula, we first determine whether the calculated optima in the corporate tax regime miss the threshold. We again assume $\alpha_{A}=\alpha_{B}=0$ and differentiate between $\tau_{A}>\tau_{B}$ and $\tau_{A}<\tau_{B}$. We focus on the relevant cases where the high-tax country initiates minimum taxation. Note that throughout the paper we consistently assume that both countries accept a tax payment that results from the most favorable transfer price (from their respective perspective) within the allowed interval $\left(t \in\left[c_{A}, d_{B}-s_{B}+\alpha_{B} s_{A}\right]\right)$. Since a transfer price of $c_{A}\left(p_{B}-c_{T}\right)$ is already chosen under corporate taxation if $\tau_{A}>\tau_{B}\left(\tau_{A}<\tau_{B}\right)$, there is no reason to apply the minimum tax formula for country $B$ (country $A$ ) if they are the low-tax country.

1. If $\tau_{A}>\tau_{B}$, the optimal transfer price under corporate income taxation is $t^{*}=c_{A}$ and optimal sales quantities are $s_{A}^{*}=\frac{1}{2}\left(d_{A}-c_{A}\right)$ and $s_{B}^{*}=\frac{1}{2}\left(d_{B}-c_{A}-c_{T}\right)$.

Thus, the reported profit in country $A$ equals

$$
\begin{aligned}
& \Pi_{A}^{n o}=\left(d_{A}-\frac{1}{2}\left(d_{A}-c_{A}\right)\right) \frac{1}{2}\left(d_{A}-c_{A}\right)+c_{A} \frac{1}{2}\left(d_{B}-c_{A}-c_{T}\right) \\
& -c_{A}\left(\frac{1}{2}\left(d_{A}-c_{A}\right)+\frac{1}{2}\left(d_{B}-c_{A}-c_{T}\right)\right)=\frac{1}{4}\left(d_{A}-c_{A}\right)^{2}
\end{aligned}
$$

An application of the sales formula according to (4) would lead to the following profit allocated to country $A$ :

$$
\frac{\left(d_{A}^{2}-c_{A}^{2}\right)\left[2 c_{A}\left(c_{A}+c_{T}-d_{A}-d_{B}\right)+d_{A}^{2}+\left(c_{T}-d_{B}\right)^{2}\right]}{4\left[d_{A}^{2}+d_{B}^{2}-\left(c_{A}+c_{T}\right)^{2}-c_{A}^{2}\right]}
$$

Comparing (78) and (79) we find that the reported profit in country $A$ is lower than the the profit according to the formula if

$$
d_{B}>\left(1+\frac{c_{T}}{c_{A}}\right) d_{A}
$$

Consequently, country $A$ applies the formula if this condition is fulfilled. As long as country $B$ continues to accept the reported profit as a basis of taxation the 
following profit function holds:

$$
\begin{aligned}
& \Pi=\left(d_{A}-s_{A}\right) s_{A}+t s_{B}-c_{A}\left(s_{A}+s_{B}\right)-\frac{\left(d_{A}-s_{A}\right) s_{A}}{\left(d_{A}-s_{A}\right) s_{A}+\left(d_{B}-s_{B}\right) s_{B}} \tau_{A} \\
& \cdot\left[\left(d_{A}-s_{A}\right) s_{A}+\left(d_{B}-s_{B}\right) s_{B}-c_{A}\left(s_{A}+s_{B}\right)-c_{T} s_{B}\right] \\
& +\left[\left(d_{B}-s_{B}\right) s_{B}-t s_{B}-c_{T} s_{B}\right]\left(1-\tau_{B}\right)
\end{aligned}
$$

The first derivative with regard to the transfer price $t$ yields

$$
\frac{\delta \Pi}{\delta t}=s_{B} \tau_{B}
$$

The profit of the $M N E$ strictly increases in the transfer price $t$ as long as a unilateral minimum taxation in country $A$ is applied. Thus, one potential optimum could be reached by increasing $t$ to $p_{B}-c_{T}$. Since $p_{B}-c_{T}$ is the most favorable transfer price for country $A$ within the allowed interval this transfer price would be accepted by country $A$ even if an application of the sales formula would lead to an even higher taxable income.

$$
\begin{aligned}
& {\left[\left(d_{A}-s_{A}\right) s_{A}+t s_{B}-c_{A}\left(s_{A}+s_{B}\right)\right]\left(1-\tau_{A}\right)} \\
& +\left[\left(d_{B}-s_{B}\right) s_{B}-t s_{B}-c_{T} s_{B}\right]\left(1-\tau_{B}\right) \\
& \geq\left(d_{A}-s_{A}\right) s_{A}+t s_{B}-c_{A}\left(s_{A}+s_{B}\right)-\frac{\left(d_{A}-s_{A}\right) s_{A}}{\left(d_{A}-s_{A}\right) s_{A}+\left(d_{B}-s_{B}\right) s_{B}} \tau_{A} \\
& \cdot\left[\left(d_{A}-s_{A}\right) s_{A}+\left(d_{B}-s_{B}\right) s_{B}-c_{A}\left(s_{A}+s_{B}\right)-c_{T} s_{B}\right] \\
& +\left[\left(d_{B}-s_{B}\right) s_{B}-t s_{B}-c_{T} s_{B}\right]\left(1-\tau_{B}\right)
\end{aligned}
$$

From the $M N E^{\prime}$ s perspective, the reported optimal after-tax profit for any given transfer price $t$ always equals or exceeds the optimal after-tax profit if the formula is applied. Therefore, the MNE would have no incentive to deviate from the optimal sales quantities derived in Lemma 2 for a transfer price of $p_{B}-c_{T}$ as long as country $B$ would accept the reported profit based on a transfer price $t=p_{B}-c_{T}$ as well.

To test whether such a solution with a transfer price at the upper end of the allowed interval would be accepted by country $B$, we compare the reported profit in country $B$ with $t=p_{B}-c_{T}, s_{A}^{*}=\frac{1}{2}\left(d_{A}-c_{A}\right)$ and $s_{B}^{*}=\frac{1}{2}\left(d_{B}-c_{A}-c_{T}\right)$ with the profit allocated to country $B$ according to the formula. 


$$
\begin{aligned}
\Pi_{B}^{n o} & =p_{B} s_{B}^{*}-\left(p_{B}-c_{T}\right) s_{B}^{*}-c_{T} s_{B}^{*}=0 \\
& <\frac{p_{B} s_{B}^{*}}{p_{A} s_{A}^{*}+p_{B} s_{B}^{*}}\left(\Pi_{A}^{n o}+\Pi_{B}^{n o}\right) \forall s_{A}^{*}, s_{B}^{*}>0
\end{aligned}
$$

Thus, a unilateral minimum taxation in country $A$ is never an optimal solution if $\tau_{A}>\tau_{B}$. As country $B$ would not accept the reported profit resulting from that solution, the sales formula is applied in both countries.

2. If $\tau_{A}<\tau_{B}$, the optimal transfer price under corporate income taxation is $t^{*}=p_{B}-$ $c_{T}$ and optimal sales quantities are $s_{A}^{*}=\frac{1}{2}\left(d_{A}-c_{A}\right)$ and $s_{B}^{*}=\frac{1}{2}\left(d_{B}-c_{A}-c_{T}\right)$.

Thus, the reported profit in country $B$ equals

$$
\begin{aligned}
& \Pi_{B}^{n o}=\left(d_{B}-\frac{1}{2}\left(d_{B}-c_{A}-c_{T}\right)\right) \frac{1}{2}\left(d_{B}-c_{A}-c_{T}\right) \\
& -\left(d_{B}-\frac{1}{2}\left(d_{B}-c_{A}-c_{T}\right)-c_{T}\right) \frac{1}{2}\left(d_{B}-c_{A}-c_{T}\right) \\
& -c_{T} \frac{1}{2}\left(d_{B}-c_{A}-c_{T}\right) \\
& =0 \\
& \quad \Pi_{B}^{n o}<\frac{p_{B} s_{B}^{*}}{p_{A} s_{A}^{*}+p_{B} s_{B}^{*}}\left(\Pi_{A}^{n o}+\Pi_{B}^{n o}\right) \forall s_{A}^{*}, s_{B}^{*}>0
\end{aligned}
$$

Since the reported profit in country $B$ is always lower than the profit allocated to $B$ according to the formula, minimum taxation is applied.

Let's assume that minimum taxation is applied unilaterally in country $B$. Then, the following profit function holds:

$$
\begin{aligned}
& \Pi=\left[\left(d_{A}-s_{A}\right) s_{A}+t s_{B}-c_{A}\left(s_{A}+s_{B}\right)\right]\left(1-\tau_{A}\right) \\
& +\left[\left(d_{B}-s_{B}\right) s_{B}-t s_{B}-c_{T} s_{B}\right]-\frac{\left(d_{B}-s_{B}\right) s_{B}}{\left(d_{A}-s_{A}\right) s_{A}+\left(d_{B}-s_{B}\right) s_{B}} \tau_{B} \\
& {\left[\left(d_{A}-s_{A}\right) s_{A}+\left(d_{B}-s_{B}\right) s_{B}-c_{A}\left(s_{A}+s_{B}\right)-c_{T} s_{B}\right]}
\end{aligned}
$$

The first derivative with regard to the transfer price $t$ yields

$$
\frac{\delta \Pi}{\delta t}=-s_{B} \tau_{A}
$$

The profit of the $M N E$ strictly decreases in the transfer price $t$ as long as a unilateral minimum taxation in country $B$ is applied. Thus, one potential optimum could be 
reached by choosing the minimal $t=c_{A}$. Country $B$ always accepts $t=c_{A}$ as it is the most favorable transfer price for it within the allowed interval. If country $A$ would accept the reported profit based on a transfer price $t=c_{A}$ as well, the $M N E$ would have no incentive to deviate from the optimal sales quantities derived in Lemma 2 for this transfer price.

To test whether such a solution would be accepted by country $A$, we compare the reported profit in country $A$ with $t=c_{A}, s_{A}^{*}=\frac{1}{2}\left(d_{A}-c_{A}\right)$ and $s_{B}^{*}=$ $\frac{1}{2}\left(d_{B}-c_{A}-c_{T}\right)$ with the profit allocated to country $A$ according to the formula. As shown in (78), the reported profit in country $A$ would be $\frac{1}{4}\left(d_{A}-c_{A}\right)^{2}$. (79) shows that the profit allocated to $A$ according to the sales formula would be

$$
\frac{\left(d_{A}^{2}-c_{A}^{2}\right)\left[2 c_{A}\left(c_{A}+c_{T}-d_{A}-d_{B}\right)+d_{A}^{2}+\left(c_{T}-d_{B}\right)^{2}\right]}{4\left[d_{A}^{2}+d_{B}^{2}-\left(c_{A}+c_{T}\right)^{2}-c_{A}^{2}\right]}
$$

The reported profit in $A$ equals or exceeds the profit allocated according to the formula if

$$
d_{B} \leq\left(1+\frac{c_{T}}{c_{A}}\right) d_{A}
$$

Thus, if $d_{B} \leq\left(1+\frac{c_{T}}{c_{A}}\right) d_{A}$ country $A$ taxes the reported profit with $t=c_{A}, s_{A}^{*}=$ $\frac{1}{2}\left(d_{A}-c_{A}\right)$ and $s_{B}^{*}=\frac{1}{2}\left(d_{B}-c_{A}-c_{T}\right)$. Country $B$ uses minimum taxation, forcing the $M N E$ to adjust the transfer price from $p_{B}-c_{T}$ to $c_{A}$ compared to the corporate tax regime. If $d_{B}$ exceeds this threshold, the sales based formula is applied in both countries.

To determine the impact of minimum taxation on the location decision of the MNE we compare the resulting after-tax profits under minimum taxation $\left(\Pi^{\mathrm{min}}\right)$ and under decentralized production $\left(\Pi^{\text {dec }}\right)$ that is based on the optimal sales quantities 
under decentralized production derived in Lemma 2).

$$
\begin{aligned}
& \Pi^{\text {min }}-\Pi^{\text {dec }} \\
& =\left\{\left[d_{A}-\frac{1}{2}\left(d_{A}-c_{A}\right)\right] \frac{1}{2}\left(d_{A}-c_{A}\right)-\frac{1}{2} c_{A}\left(d_{A}-c_{A}\right)\right\}\left(1-\tau_{A}\right) \\
& +\left\{\left[d_{B}-\frac{1}{2}\left(d_{B}-c_{A}-c_{T}\right)-c_{A}-c_{T}\right] \frac{1}{2}\left(d_{B}-c_{A}-c_{T}\right)\right\}\left(1-\tau_{B}\right) \\
& -\left\{\left[d_{A}-\frac{1}{2}\left(d_{A}-c_{A}\right)-c_{A}\right] \frac{1}{2}\left(d_{A}-c_{A}\right)\right\}\left(1-\tau_{A}\right) \\
& -\left\{\left[d_{B}-\frac{1}{2}\left(d_{B}-c_{B}\right)-c_{B}\right] \frac{1}{2}\left(d_{B}-c_{B}\right)\right\}\left(1-\tau_{B}\right)
\end{aligned}
$$

Solving for $c_{B}$ shows that

$$
\Pi^{\text {min }}>\Pi^{\text {dec }} \text { for } c_{B}>c_{A}+c_{T}
$$

Thus, a centralized solution under a unilateral minimum taxation regime in country $B$ is preferred to decentralized production if $c_{B}>c_{A}+c_{T}$.

Tax revenues $\mathcal{T}_{A}$ and $\mathcal{T}_{B}$ in country $A$ and $B$ for an optimal transfer price $t^{*}=c_{A}$ can be inferred from (12) and (13) for centralized production and for the tax rate differential $\tau_{A}>\tau_{B}$.

\section{A.4. Proofs of Section 3.2}

Under centralized production, the optimal sales quantity $s_{B}^{*}$ after the implementation of corporate taxation (see (30)) is higher compared to the pre-tax regime (see (24)) if the following condition holds:

$$
\frac{1}{2\left(\tau_{A}+\tau_{B}-2\right)\left(c_{A}-d_{A}\right)} *\left[\left(\tau_{A}-\tau_{B}\right)\left(c_{A}-d_{B}+c_{T}\right)+\sqrt{\psi}\right]<\alpha
$$

with

$$
\begin{aligned}
\psi & =\left(\tau_{A}-\tau_{B}\right)^{2}\left(c_{T}-d_{B}\right)^{2} \\
& +2 c_{A}\left[\left(\tau_{A}-\tau_{B}\right)^{2}\left(c_{T}-d_{B}\right)-8 d_{A}\left(\tau_{A}-1\right)\left(\tau_{A}+\tau_{B}-2\right)\right] \\
& +c_{A}^{2}\left(3 \tau_{A}+\tau_{B}-4\right)^{2}+8 d_{A}^{2}\left(\tau_{A}-1\right)\left(\tau_{A}+\tau_{B}-2\right)
\end{aligned}
$$

Under decentralized production, the optimal sales quantity $s_{B}^{*}$ is higher after the implementation of corporate taxation (see (32)) compared to the pre-tax regime (see 
(24)) if the following condition holds:

$$
\frac{1}{2\left(\tau_{A}+\tau_{B}-2\right)\left(c_{A}-d_{A}\right)} *\left[\left(\tau_{A}-\tau_{B}\right)\left(c_{B}-d_{B}\right)+\sqrt{\zeta}\right]<\alpha
$$

with

$$
\begin{aligned}
\zeta & =-16 c_{A} d_{A}\left(\tau_{A}-1\right)\left(\tau_{A}+\tau_{B}-2\right)+\left(\tau_{A}-\tau_{B}\right)^{2}\left(c_{B}-d_{B}\right)^{2} \\
& +8 c_{A}^{2}\left(\tau_{A}-1\right)\left(\tau_{A}+\tau_{B}-2\right)+8 d_{A}^{2}\left(\tau_{A}-1\right)\left(\tau_{A}+\tau_{B}-2\right)
\end{aligned}
$$

\section{A.5. Proof of Lemma 6}

The analysis of a minimum taxation regime with complementarities between national sales $\left(\alpha_{i}>0\right)$ follows systematically the same procedure as for $\alpha_{A}=\alpha_{B}=0$.

1. If $\tau_{A}>\tau_{B}$, the optimal transfer price under corporate income taxation is $t^{*}=c_{A}$ and optimal sales quantities are given by (27) and (28). Country $A$ applies the sales formula if reported profits in $A$ (i.e., $\left.\left(p_{A}-c_{A}\right) * s_{A}\right)$ are lower than taxable profits according to the formula (i.e. $\frac{p_{A} * S_{A}}{p_{A} * S_{A}+p_{B} * S_{B}} * \Pi^{n o}$ ). We insert both $t^{*}=c_{A}$ and the optimal sales quantities to determine the threshold that has to be exceeded to warrant an application of the formula by country A.

$$
d_{B}>\frac{\eta}{\theta}
$$

with

$$
\begin{aligned}
\eta & =\alpha_{B}\left(1-\tau_{B}\right) c_{A}\left[\left(1+\alpha_{A}\right) d_{A}\left(1-\tau_{A}\right)-2\left(1-\tau_{B}\right) c_{T}\right] \\
& +\alpha_{B}\left(1-\tau_{B}\right) c_{T}\left[\alpha_{A} d_{A}\left(1-\tau_{A}\right)-\left(1-\tau_{B}\right) c_{T}\right] \\
& -\alpha_{B}\left(1-\tau_{B}\right) c_{A}^{2}\left(2-\tau_{A}-\tau_{B}\right) \\
& +\left(1-\tau_{A}\right) \alpha_{A} c_{A}^{2}\left[2+\alpha_{A}-\left(1+\alpha_{A}\right) \tau_{A}-\tau_{B}\right] \\
& -\left(1-\tau_{A}\right) c_{A}\left[\alpha_{A}\left(1-\tau_{A}\right)-2 \tau_{B}+2\right]\left(d_{A}-\alpha_{A} c_{T}\right) \\
& -\left(1-\tau_{A}\right)\left(1-\tau_{B}\right) c_{T}\left(2 d_{A}-\alpha_{A} c_{T}\right) \\
& +\alpha_{B}^{2}\left(1-\tau_{B}\right)^{2}\left(d_{A}-c_{A}\right)\left(c_{A}+c_{T}\right)
\end{aligned}
$$

and

$$
\begin{aligned}
\theta & =c_{A}\left[\alpha_{A}^{2}\left(1-\tau_{A}\right)^{2}-\left(2-\alpha_{A}-\alpha_{A} \alpha_{B}\right)\left(1-\tau_{A}\right)\left(1-\tau_{B}\right)-\alpha_{B}\left(1-\tau_{B}\right)^{2}\right] \\
& +c_{T}\left(1-\tau_{B}\right)\left(\alpha_{A}\left(1-\tau_{A}\right)-\alpha_{B}\left(1-\tau_{B}\right)\right)
\end{aligned}
$$


As shown in (82), the MNE has incentives to increase its transfer price as long as country $A$ unilaterally applies minimum taxation. Therefore, a potential optimum could be a situation where a transfer price $t=p_{B}-c_{T}$ is chosen, which would be accepted by country $A$ because it represents the highest price within the allowed interval. However, (84) shows that a transfer price of $p_{B}-c_{T}$ is not accepted by country $B$ since its taxable income would be zero. Therefore, for any positive sales quantities $s_{B}$ country $B$ is better off when it applies the sales formula. The sales formula is thus always applied in both countries for $\tau_{A}>\tau_{B}$ if the condition in (95) is fulfilled.

2. If $\tau_{A}<\tau_{B}$, the optimal transfer price under corporate income taxation is $t^{*}=p_{B}-$ $c_{T}$ and optimal sales quantities follow from (29) and (30). Since for the applied tax rate differential the reported profit in country $B$ is zero $\Pi_{B}^{n o}=0$ (as shown in (85)), country B would always apply minimum taxation. The profit of the MNE strictly decreases in the transfer price if unilateral minimum taxation is applied in country $\mathrm{B}$ (see (88)). Thus, as shown for $\alpha_{A}=\alpha_{B}=0$, one potential optimum could be reached by setting $t=c_{A}$. Country B always accepts that transfer price. By comparing the reported profit in country A under $t=c_{A}$ with the profit allocated to country A according to the formula we test whether country A would accept such a solution. We thereby insert the optimal sales quantities for $t=c_{A}$ known from (27) and (28). As shown in (95), country A accepts the transfer price and does not apply the formula as long as $d_{B}$ is below or equal to the threshold $\frac{\eta}{\theta}$. In this case, the implementation of minimum taxation results in an adjustment of both the transfer price and the sales quantities. Under corporate taxation, the optimal sales quantities were given by (29) and (30). After the implementation of minimum taxation they are given by (27) and (28). This adaptation in sales quantities is unique for a setting with complementarities in sales (i.e. $\alpha_{A}>0$ and $\alpha_{B}>0$ ). If the condition of (95) is fulfilled, the sales based formula is applied in both countries.

\section{A.6. Proof of Section 3.3}

To show that the tax revenue $\mathcal{T}_{A}$ can both increase or decrease under minimum taxation compared to a corporate taxation regime we assume $\tau_{A}<\tau_{B}$ and $\alpha_{A}=\alpha_{B}=\alpha$. Moreover, $c_{B}$ is supposed to be sufficiently high to warrant centralized production under both a corporate tax and and a minimum taxation regime. Specifically, we assume the 
following parameter setting:

$$
d_{A} \rightarrow 2,000 ; c_{A} \rightarrow 11 ; c_{T} \rightarrow 30 ; \tau_{A} \rightarrow 0.15 ; \tau_{B} \rightarrow 0.3 ; \alpha \rightarrow 0.5
$$

To calculate the tax revenue $\mathcal{T}_{A}$ under a corporate income taxation regime, we insert the optimal transfer price $t^{*}=p_{B}-c_{T}$ and the optimal sales quantities $s_{A}^{*}$ (see (29)) and $s_{B}^{*}($ see $((30))$.

$$
\begin{aligned}
\mathcal{T}_{A} & =\tau_{A}\left(p_{A}^{*} s_{A}^{*}+t^{*} s_{B}^{*}-c_{A}\left(s_{A}^{*}+s_{B}^{*}\right)\right) \\
& =0.05 d_{B}^{2}+95.35 d_{B}+193,813
\end{aligned}
$$

Equivalently, for a minimum taxation regime we insert the optimal transfer price $t^{*}=$ $c_{A}$ and the optimal sales quantities $s_{A}^{*}$ and $s_{B}^{*}$ from equations (35) and (36). The tax revenue $\mathcal{T}_{A}$ yields as:

$$
\begin{aligned}
\mathcal{T}_{A} & =\tau_{A}\left(p_{A}^{*} s_{A}^{*}+t^{*} s_{B}^{*}-c_{A}\left(s_{A}^{*}+s_{B}^{*}\right)\right) \\
& =0.0013 d_{B}^{2}+52.7429 d_{B}+20,2749
\end{aligned}
$$

Equalizing (96) and (97) shows that tax revenues in $A$ under the minimum tax regime are equal to the ones under a corporate income tax regime if $d_{B}=174.828$. If $d_{B}<174.828\left(d_{B}>174.828\right)$, tax revenues $\mathcal{T}_{A}$ decrease (increase) under a minimum taxation regime compared to a corporate income tax regime. The condition in Lemma 6 is fulfilled as long as $d_{B}<10,475$. Thus, both an increase or a decrease of $\mathcal{T}_{A}$ are possible depending on the specific parameter setting. 


\section{References}

Alchian, A. and Demsetz, H. (1972). Production, information costs, and economic organization. The American Economic Review, 62(5):777-795.

Andrus, J. and Oosterhuis, P. (2017). Transfer Pricing after BEPS: Where are we and where should we be going. Taxes, 95 .

Best, M., Brockmeyer, A., Kleven, H., Spinnewijn, J., and Waseem, M. (2015). Production versus revenue efficiency with limited tax capacity: Theory and evidence from Pakistan. Journal of Political Economy, 123(6):1311-1355.

Bunn, D. (2021). Two important issues that must be resolved in global tax reform. https://taxfoundation.org/us-global-minimum-tax/.

Clausing, K. A. (2016). The US state experience under formulary apportionment: are there lessons for international reform? National Tax Journal, 69(2):353-386.

Cui, W. and Hashimzade, N. (2019). The digital services tax as a tax on location-specific rent. CESifo Working Paper No. 7737.

Dyreng, S. D. and Maydew, E. L. (2018). Virtual issue on tax research published in the Journal of Accounting Research. Journal of Accounting Research.

Goolsbee, A. and Maydew, E. L. (2000). Coveting thy neighbor's manufacturing: the dilemma of state income apportionment. Journal of Public Economics, 75(1):125-143.

GrantThornton (2019). Digital services tax in Europe. Grant Thornton International Ltd.

Hein, A., Schreieck, M., Riasanow, T., Setzke, D. S., Wiesche, M., Boehm, M., and Krcmar, H. (2020). Digital platform ecosystems. Electronic Markets, 30:87-98.

Li, J. (2018). Protecting the tax base in a digital economy. Osgoode Legal Studies Research Paper No. 78 Vol. 13/ Issue. 17.

Marques, M., Pinho, C., and Menezes Montenegro, T. (2019). The effect of international income shifting on the link between real investment and corporate taxation. Journal of International Accounting, Auditing and Taxation, 36:??

Martini, J. T., Niemann, R., and Simons, D. (2012). Transfer pricing or formula apportionment? Tax-induced distortions of multinationals' investment and production decisions. Contemporary Accounting Research, 29(4):1060-1086.

Merle, R. (2016). Why McDonald's and Google are in trouble in Europe. The Washington Post, 5/31/2016.

Norris, F. (2013). Apple's move keeps profit out of reach of taxes. The New York Times $5 / 2 / 2013$ 
OECD (2018). Multinational enterprises in the global economy - Heavily debated but hardly measured. https://www.oecd.org/industry/ind/MNEs-in-the-globaleconomy-policy-note.pdf.

OECD (2021). Statement on a Two-Pillar Solution to Address the Tax Challenges Arising From the Digitalisation of the Economy. https://www.oecd.org/tax/beps/statementon-a-two-pillar-solution-to-address-the-tax-challenges-arising-from-thedigitalisation-of-the-economy-july-2021.pdf.

Radaelli, C. M. and Klemm, A. (2001). EU Corporate Tax Reform: Report of a CEPS Task Force (Vol. 40). CEPS.

Scot, T., Lobel, F., and Zuniga, P. (2020). Corporate taxation and evasion responses: Evidence from a minimum tax in honduras. Working Paper, 113th Annual Conference on Taxation. NTA. 